\title{
Genuine diversity? The Broom biface assemblage
}

Article

Accepted Version

Hosfield, R. and Chambers, J. C. (2009) Genuine diversity?

The Broom biface assemblage. Proceedings of the Prehistoric Society, 75. pp. 65-100. ISSN 0079-497X Available at https://centaur.reading.ac.uk/16457/

It is advisable to refer to the publisher's version if you intend to cite from the work. See Guidance on citing.

Publisher: Prehistoric Society

All outputs in CentAUR are protected by Intellectual Property Rights law, including copyright law. Copyright and IPR is retained by the creators or other copyright holders. Terms and conditions for use of this material are defined in the End User Agreement.

\section{www.reading.ac.uk/centaur}

\section{CentAUR}

Central Archive at the University of Reading

Reading's research outputs online 


\title{
GENUINE DIVERSITY? THE BROOM BIFACE ASSEMBLAGE
}

\section{DR ROBERT HOSFIELD \& DR JENNIFER CHAMBERS}

Dr Robert Hosfield: Dept. of Archaeology, School of Human \& Environmental Sciences, University of Reading, Whiteknights, Reading, RG6 6AB, UK. E-mail: r.hosfield@rdg.ac.uk Dr Jennifer Chambers: Flat One, 111 Anderton Park Road, Birmingham, B13 9DQ, UK. Email: jennichambers@hotmail.com

\begin{abstract}
The Broom Lower Palaeolithic locality, on the river Axe at the Devon/Dorset border in southwestern Britain, yielded an assemblage of at least 1,800 Acheulean artefacts between the 1870s and 1940s through gravel quarrying and antiquarian collection. The bifacial material, predominantly produced in chert but including a small flint component, is characterised by considerable typological diversity and a distinctive asymmetrical element. While aspects of the assemblage have been reported before (Roe 1968; Green 1988; Marshall 2001), this paper presents new work on the artefacts of the C.E. Bean collection, held at The Dorset County Museum (Green 1988), and the sample from Exeter Museum (Royal Albert Memorial Museum and Art Gallery). The Bean archive indicates that the artefact patterning is not due to fluvial mixing of separate, typologically-discrete, assemblages. Analysis of the artefacts suggests that hominin knapping strategies were not notably constrained by variations in raw material granular quality, but that the typological variability strongly reflects blank form and shape (White 1998a). However, while the influences of blank form and re-sharpening, including the use of tranchet flaking, partially explain the assemblage's asymmetrical component, a significant proportion of those artefacts cannot be understood in these terms. The existence of local, short-lived manufacturing traditions, perhaps reflecting the idiosyncratic approaches of individual knappers, is argued to best explain the distinctive asymmetrical element of the Broom assemblage. This interpretation is further supported by (i) the geoarchaeological model of assemblage formation, which assigns the majority of the artefacts to a single phase of occupation (cf. Hosfield 2005), and (ii) the OSL ages of the Broom fluvial deposits (predominantly MIS-9 and 8) and the atypical character of the
\end{abstract}


assemblage in relation to other British late Lower Palaeolithic material, which oppose the notion of longer-lived, locally or regionally-maintained, traditions.

\section{INTRODUCTION}

Recent discussions of Acheulean biface variability have explored a wide range of factors, including raw material quality and blank form (e.g. Ashton \& McNabb 1994; White 1998a; Wenban-Smith et al. 2000; Shaw \& White 2003), re-sharpening intensity (e.g. McPherron 1995, 2006; Ashton 2001, 2008), and the possibilities of distinctive regional (e.g. White 1998b; Clark 2001: 5-13; McNabb 2001: 41-44 \& Table 4.3; McNabb et al. 2004: 667; Petraglia et al. 2005: 202-207; Villa 2001: 122) and/or chronological (e.g. White 1998b; Wenban-Smith 2004) trends, while there has also been a wider, but potentially complementary, interest in the issues of social learning and transmission mechanisms (e.g. Mithen 1994, 1996, 1999; Roux \& Bril 2005), and the identification of individuals' artefacts (e.g. White \& Plunkett 2004; Hopkinson \& White 2005: 22-24; Pope et al. 2006: 51-52). In light of these developments new work examining the Acheulean biface assemblage from the site of Broom in south-west Britain is presented. Its geographical location on the northwestern margins of the Acheulean world, the potentially late Acheulean date of the assemblage, use of a relatively atypical British Lower Palaeolithic raw material (chert), and the notable presence of morphological planform asymmetry are all worthy of review in light of current research directions.

The Lower Palaeolithic artefact assemblage at Broom was recovered from Middle Pleistocene terrace deposits of the river Axe, which lie upon a Lower Lias shales and marls bedrock, at the junction between the Axe and its east bank tributary the Blackwater (Figures $1 \& 2$ ). The deposits have been principally exposed in three commercially-worked gravel pits, the Railway Ballast Pit (ST 326020), Pratt's New Pit (ST 328024), and Pratt's Old Pit (ST 328025; Figure 2). Artefacts have been collected from the deposits at Broom since at least the early 1870 s (Evans 1872: 559), and most notably during the 1930 s by C.E. Bean, F.S.A., the surveyor for Sherborne (Moir 1936; Green 1988), while two further bifaces were recovered during 
fieldwork by Green, Shakesby and Stephens in the early 1980s (Shakesby \& Stephens 1984: 86 \& Fig. 3).

The different phases of collecting have yielded a large number of artefacts relative to the remaining Lower Palaeolithic assemblages of south-west Britain (Wymer 1999: 181-188; Hosfield et al. 2006; Hosfield et al. 2007: Section 2.8). An exact tally of artefacts remains difficult to establish, reflecting their dispersal to private, museum and university collections throughout the country. However recent analysis of Exeter's Royal Albert Memorial Museum and Art Gallery collection $(n=305)$ and the C.E. Bean collection at The Dorset County Museum ( $n=1,122$ : based on both Green (1988) and Hosfield \& Chambers (2004): DORCM 1986.40.1-4), combined with Marshall's (2001) sampling of 239 bifaces from the British Museum collections, and 168 artefacts identified in other museums through the Palaeolithic Rivers of South-West Britain project (Hosfield et al. 2007) suggests a minimum of 1,803 artefacts (31 items in the C.E. Bean collection are natural clasts), of which 1,547 (86.3\%) were whole bifaces (with a further 71 biface fragments and roughouts). While the Southern Rivers Palaeolithic Project suggested a similar artefact total of 1,807 (Wessex Archaeology 1993: 163), 1,804 of these are listed as bifaces, suggesting that the actual total of Broom artefacts is larger still. This paper discusses the Exeter $(n=260)$ and Bean collection $(n=767)$ bifaces, recovered both from the Railway Ballast Pit and, as part of C.E. Bean's collecting, from Pratt's New Pit and Pratt's Old Pit during the 1930s and 1940s (Green 1988: 176-180).

In Bean's recording of his own biface assemblage $(n=898$; previously summarised in Green 1988: Fig. 5 \& Table 1; Hosfield \& Chambers 2004: 135-137) he highlighted a 'lop-sided' or asymmetrical ovate/cordate (after Wymer 1968: Fig. 27), or typical amygdaloid form (after Bordes 1961; Debénath \& Dibble 1994: 146-147; Bean's type 4: $n=457,50.9 \%)$, along with a range of other types (Figure 3), of which types $10(n=109,12.1 \%), 3(n=76,8.5 \%), 5(n=65$, $7.2 \%)$ and $16(n=62,6.9 \%)$ were the most prevalent. This diversity in the Broom bifaces was reflected in Roe's (1968: 11 \& 61, Table I, IV \& V, Figs. 19 \& 48) metrical analysis of 172 bifaces from Broom, which concluded that Broom has a very 'generalized' industry, combining "extreme pointed handaxes with flat, refined ovate types, with enough of each to make it hard 
to decide whether they belong on the one hand with the 'more pointed' ovate group, or on the other with Hoxne, Hitchin and Dovercourt in the Pointed Tradition" (Roe 1968: 61).

The principal point of current interest concerns the apparently high incidence of asymmetrical (Bean's 'lop-sided') bifaces within the Broom assemblage (comparative data from selected other British assemblages are included in Table 1), particularly in light of recent studies that have explored symmetry in terms of sexual selection theory (Kohn \& Mithen 1999; but see also Machin 2008; Mithen 2008; Nowell \& Chang 2009), display (Machin 2009: 43-45), functional advantages for butchery (Machin et al. 2005, 2007), and individual preference (Ashton \& White 2003: 118). In light of these and other recent developments in Acheulean studies this paper explores whether the prevalence of asymmetrical forms in the Broom assemblage reflects:

- Relatively 'short'-lived traditions of production, following White's (1998b) focus on the 'concentrated' (typically 20-40\%) occurrence of twisted ovate handaxes in MIS-11 assemblages and the potential contribution of geographical isolation to that pattern (White \& Schreve 2000: 20-22). An important element in the evaluation of a 'traditions' model at Broom concerns the formation of the assemblage within a river gravel context, and the vertical and horizontal distribution of the artefacts through the sedimentary sequence, with reference both to the overall assemblage and the different biface types. At a regional scale consideration of the potential 'isolation' of western Britain at various times during the Middle Pleistocene is also an important factor.

- Specific techniques of production, following the recent interest in regionally-distinctive biface blank production techniques (e.g. Villa 2001: 122; Petraglia et al. 2005: 202-207; Sharon 2007, 2008). Such possibilities were first explored by C.E. Bean in his suggestion that the bulge or swelling on the 'lop-sided' Broom bifaces generally contained a platform or the site of a knapping platform and might show technological affinities with the sidestruck (hoenderbek) flakes of the Victoria West tradition in the African Acheulean (e.g. Goodwin 1929; McNabb 2001; Sharon \& Beaumont 2006). 
- Raw material factors, highlighted by recent discussions regarding the relative importance of raw material availability, quality and form (e.g. Ashton \& McNabb 1994; White 1998a; Wenban-Smith et al. 2000; Shaw \& White 2003), and the role of re-sharpening in artefact curation (Ashton 2001, 2008). Broom offers an opportunity to further consider these factors, given the production of bifaces in coarse and fine-grained cherts and flint.

- The diversity of biface types in the Broom assemblage is also considered with regards to recent claims for a Late Acheulean expansion in the diversity of distinct types, both between and within assemblages (Wenban-Smith 2004).

\section{SEDIMENTARY AND GEOCHRONOLOGICAL CONTEXT}

As the Broom assemblage was recovered from a river terrace context, it is necessary to review the sedimentary and geochronological setting and clarify why this material is appropriate for answering the central research questions: can the morphological diversity and range of symmetry in the Broom bifaces be related to variability in: (i) raw material resources, incorporating re-sharpening as a potential means of resource curation; (ii) blank form; and/or (iii) traditions of production?

The Broom assemblage and deposits are located within the valley of the river Axe, which flows through south Somerset, west Dorset and east Devon, entering the English Channel at Seaton (Figure 1). The river meanders in a narrow floodplain between Chard Junction and Kilmington, the stretch including the Broom gravel pits. The river basin is characterised by comparatively flat-topped hills and low plateau. Some of the west and north-west facing escarpments are prominent, although the basin tends to lack steep slopes (Shakesby \& Stephens 1984: 77). The Axe has a steep profile, falling $25 \mathrm{~m}$ in the $10 \mathrm{~km}$ between Axminster and Seaton (Wessex Archaeology 1993: 159). Near Broom the river cuts through the Foxmould-Whitecliff Chert Member succession of the Upper Greensand Formation. The sands of the Foxmould, some 35m in thickness, contain lenticular lumps of sandy chert, while the sandstones of the Chert Beds, upto $15 \mathrm{~m}$ thick, include strongly developed chert bands (Shakesby \& Stephens 1984: 79; Edwards \& Gallois 2004: 11 \& Fig. 3). The river gravels predominantly contain chert clasts (Edwards \& Gallois 2004: 17). Other lithic raw materials in 
this region are relatively rare, restricted to river gravel flint cobbles and the fresh flint Chalk outcrops at Beer, Furley/Membury, and Widworthy/Kilmington (Newberry 2002).

The fluvial deposits of the river Axe exposed at Broom underlie the terrace surface at $c .60 \mathrm{~m}$ OD (Campbell et al. 1998: 311), to a thickness of at least 15m, and extending below $45 \mathrm{~m}$ OD to an unknown depth (ibid: 311-312). During the 1930s working of Pratt's Old Pit, C.E. Bean recorded the exposed stratigraphy in sketches and photographs and concluded with Moir (1936: Fig. 1) that the deposit was tripartite, with "stratified gravel and old land surfaces" lying between 'cherty' gravels above and 'flinty' gravel below. They also argued that fresh palaeoliths were coming from the middle beds (the "stratified gravel and old land surfaces") and derived palaeoliths mainly from the gravels above. Moir's overall composite stratigraphy for Broom, at least partially based upon Bean's observations and records (Moir 1936: 266), was recently summarised by Campbell et al. (1998: 311):

4. Surface soil.

3. Tumbled coarse gravels with partings of sandy clay and clayey matrix $(7.6 \mathrm{~m})$.

2. Stratified gravel with clayey sand and sandy seams, some black bands $(2.4 \mathrm{~m})$.

1. Unstratified sand and gravel $(5.2 \mathrm{~m})$.

During the late 1970s and early 1980s, new investigations (Shakesby \& Stephens 1984; Green 1988; Figure 2) re-exposed the principal deposits and confirmed the geological observations of Bean and Moir. Their descriptions of the three units are briefly summarised here, following Campbell et al. (1998: 311-313) and Green (1988: 175-176):

The Upper Gravels: This unit is less regularly stratified than the Lower Gravel. It is generally coarse and reddish in colour, while seams, lenses and masses of sand or loam, often green in colour, are common. The Upper Gravels are chert-rich, in contrast to the Lower Gravels. Up to $9 \mathrm{~m}$ of the Upper Gravel was exposed in Pratt's Old Pit. 
The Middle Beds: The individual beds of this unit are limited both in thickness and lateral extent. In combination they form a distinctive association, in which fine-grained sediments are more common than in either the Lower or Upper Gravels. Nonetheless, gravel is still the predominant lithology in the Middle Beds. The unit is separated by a sharp boundary from the Lower Gravel, but is generally less easy to distinguish from the Upper Gravel, forming irregular and discontinuous seams, lenses and masses in its lower part. Clays and sandy-clay or loams are common, with the clay beds typically brown in colour or less commonly greenish-grey and bluish-grey. In some cases the clay beds contain scattered stones, while streaks of black staining are occasionally recorded, usually toward the bottom of the Middle Beds. Red, green and pale-coloured sands also occur. The gravels are characterised by coarse texture and open fabric, with heavy rust-coloured or black staining. These gravel beds were referred to by Bean as the 'red beds' and are a notable feature of the Middle Beds association. The Middle Beds generally occur between c. $49.75 \mathrm{~m}$ and c. $47.6 \mathrm{~m} \mathrm{OD}$, except in the south-eastern quarter of Pratt's Old Pit, where they descend to c. $45.5 \mathrm{~m}$ OD.

The Lower Gravels: The Lower Gravel is pale-grey or white in colour. The unit is well stratified, with horizontal bedding prevalent and occasional shallow cross-beds. The clasts are mainly smaller than in the Upper Gravel, while beds and lenses of sand are less common and thinner but laterally persistent, giving a further impression of more regular bedding. There is occasional interruption of the horizontal beds by the shallow, cross-bedded units. Bean also suggested that the gravels contained more flint than chert, a conclusion supported by C.P. Green (pers. comm.). 3.5-5.0m exposures of the Lower Gravel were observed in various parts of Pratt's Old Pit, but its base was never seen.

Calkin and J.F.N. Green proposed a complex depositional model for the Broom sequence, involving two platforms cut by successive erosional stages of the Axe river, combined with associated aggradational and reworked gravels (Green 1947; Calkin \& Green 1949; Campbell et al. 1998: 314-315). However the more recent fieldwork (Shakesby \& Stephens 1984; Hosfield \& Chambers 2004: Ch. 3) has suggested a simpler, single terrace model with a temperate floodplain deposit, indicated by pollen evidence from clays in the Middle Beds, 
occurring within a series of cold-climate gravels. The 'sandwiching' of the temperate deposits between the Upper and Lower Gravels is therefore reminiscent of Bridgland's (2000) climatically-driven model of terrace formation for the Thames; but see also Hosfield et al. (2007). This implies that periglacial braided stream deposition was interrupted by the accumulation of the pollen-bearing fine-grained sediments during a period of more temperate conditions (Campbell et al. 1998: 316). The age of the Axe gravels is problematic, as the valley lacks a multiple-terrace sequence in the style of the Thames and the Solent River for example (Bridgland 1994, 2001), and there is an absence of material for biostratigraphical modelling (cf. Schreve 2001 for the Thames).

Optically Stimulated Luminescence (OSL) dating of the Broom deposits (Table 2; Toms et al. 2005) suggests that the Middle Beds and the Upper Gravels were probably deposited during late MIS-9 and MIS-8, and late MIS-9, MIS- 8 and MIS-7 respectively, while there were no open exposures of the Lower Gravels available for sampling in 2003 when the OSL work was undertaken. The OSL dating programme collected fifteen conventional sediment samples from sand and silt units occurring within the Middle Beds and the Upper Gravels, which were optically dated using conventional multi-grain single aliquot regenerative-dose measurements (Table 2; see Toms et al. 2005: 3-8 for full methodological details). Twelve of the samples yielded Middle Pleistocene ages (Table 2), while three produced Late Pleistocene age estimates which are likely to reflect re-worked materials. Three of the dates for a single exposure of the Middle Beds within the Railway Ballast Pit (GL02083: 287 \pm 22 kya; GL02084:

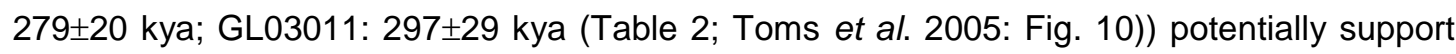
the assignment of these temperate deposits to an interstadial event within MIS-8. However the Bayesian modelling assigned the Middle Beds, at $1 \sigma$ confidence, to a mid MIS-9/mid MIS8 interval between 324-284 kya, suggesting a possible interglacial age for those sediments (Toms et al. 2005: 16-17). The Bayesian model assigned the Upper Gravels to an MIS8/MIS-7 interval (292-205 kya).

The OSL dates were amongst the oldest quoted for British Pleistocene fluvial deposits at the time of their 2005 publication, raising concerns with regards to signal saturation and retention 
(potential age underestimation) and incompatibility of large natural and laboratory induced signals (potential age overestimation; Toms et al. 2005: 8). As well as drawing upon extrapolations from previous studies (ibid: 8-9), Toms et al. plotted the bivariation of each sample's $D_{e}$ and dose rate values (Table 2). The broad linear distribution of the majority of the data from the conventional samples illustrates the comparability of the age estimates from sedimentary units of contrasting dosimetry, supporting the accuracy of these old age estimates and suggesting a limited influence of partial bleaching (ibid: 9). Bayesian modelling of the dates was also successful, with an overall agreement index $(A)$ of $102.1 \%$, when relative stratigraphic assignments were restricted to the coarse resolution of the Middle Beds and the Upper Gravels. However when the sequence of age estimates was defined in order of the elevation of each dated unit the agreement index fell to $34.3 \%$, highlighting the problems of using sample elevation as a measure of relative stratigraphic position within the context of a dynamic fluvial environment. Overall the Bayesian analysis generated age estimates consistent with stratigraphic position at a resolution analogous with the tripartite terrace sequence at Broom (ibid: 13-15).

It has been suggested that the deposits are at least partly fluvio-glacial, deriving from an icedammed lake somewhere to the north of the Chard Gap (Campbell et al. 1998: 315). Stephens (1974) emphasised the role of the Chard Gap, at 90m OD compared to the local interfluves at $230-290 \mathrm{~m} \mathrm{OD}$, in the origin of the Axe gravels, arguing that a pro-glacial lake ('Lake Maw') may have existed in the Somerset lowlands as a result of Irish Sea and Welsh ice blocking the Bristol Channel and pressing against the north Devon coast. The lake discharge may have then overflowed southwards through the Chard Gap. This discharge event would have washed masses of rock debris (and potentially Palaeolithic artefacts) into the Axe Valley, accounting for the thick gravel terrace deposits between Chard and Seaton and their absence along the upper Axe Valley east/upstream of Chard. This model follows work as far back as Maw (1864) in its view of a Bristol Channel which was once blocked with ice. Green (1974) however has challenged this interpretation, pointing out that while there are far-travelled materials in the Axe valley (principally quartz and grits), deposits of similar composition to the lower Axe terrace gravels occur in the Axe gravels above the Chard Gap 
and in the nearby Yarty and Otter valleys. These areas could not have been supplied via the Chard Gap and therefore help refute the glacial origin model (Green 1974: 217 \& 219). Green instead demonstrated similarities between the composition of the river gravels and the composition (and distribution) of the adjacent Tertiary plateau gravels, and suggested that the river deposits were largely derived from the remnant gravel patches of pre-Pleistocene age on the valley interfluves, and from the chert Head deposits on the slopes.

Moir (1936: 266 \& Fig. 1) divided the Broom artefacts into 'rolled' and 'unrolled' categories, and equated the majority of the latter with the $5^{\prime}(1.5 \mathrm{~m})$ "stratified gravel with old land surfaces" layer containing "Late Acheulean Floors", while arguing that most of the former had been derived into the Upper Gravel. The origins of the artefacts were subsequently argued by Green (1988: 180) to be local rather than in situ, with the generally unrolled condition of the artefacts suggesting that they were originally discarded onto the floodplain surface and then displaced over a short distance during low energy reworking of the floodplain. Hosfield \& Chambers (2004: 185) broadly supported this interpretation, although arguing that all of the artefacts show evidence for limited fluvial transportation (i.e. none of them are 'unrolled') and that this transport occurred in association with coarser-grained gravels and therefore higher energy conditions, as indicated by edge damage on the bifaces. This last interpretation is followed here.

\section{THE C.E. BEAN COLLECTION}

To analyse the patterning in the Broom assemblage it is also necessary to review the collection history of the Bean assemblage and the available information regarding the artefacts' stratigraphic provenance.

The C.E. Bean artefact collection and archive (The Dorset County Museum: DORCM 1986.40.1-4) was compiled from Pratt's Old Pit between 1932 and 1941, with limited work at Pratt's New Pit between 1938 and 1941 (for a fuller review see Green 1988; Hosfield \& Chambers 2004: Ch. 4; Hosfield \& Green forthcoming). Due to the absence of records for the period up to September 1933 it is not possible to plot site visits to the pit and artefact recovery 
rates for the entire period (c.f. Sampson 1978 for Caddington), although Green (1988) recorded a series of key patterns:

"Before 1935, 165 implements were acquired but few details of provenance are noted. Between February and December 1935, 24 visits were made to Broom, and 111 implements were acquired (apparent rate of recovery 0.36 implements per day). The provenance of many of these implements is recorded. In the following nine months the site was not visited. Then between September 1936 and March 1938, 17 visits were made to the site and 140 implements were acquired (apparent rate of recovery 0.26 implements per day). Provenance is infrequently recorded. During the next ten months, to the end of 1938, 507 implements were acquired (rate of recovery 1.68 implements per day). Many of these implements came from one small area [the '1938 Locality']...and details of provenance are recorded in considerable detail. After January 1939 few implements were found. The material acquired in 1941 included implements from the New Pit to the south of Holditch Lane."

(Green 1988: 177; our comments in [])

It is clear from Bean's notebook entries that much of the artefact material and the information regarding their provenance came from the workmen at Broom. Although Green (1988: 176) has argued that there is no indication that purchase prices for artefacts varied according to their provenance in the pits, Bean himself was aware of the limitations of the recorded information, observing that:

"The XXX family are prone to fabricate sites which they think will please you or enhance the values."

(C.E. Bean archive, $24^{\text {th }}$ March 1935)

Caution must therefore be given to the interpretation of artefact stratigraphy data from Broom; although Bean's professional surveying skills enable much greater confidence to be placed in his direct observations. The general quality of the artefact provenancing information in the Bean archive also varies considerably. In some cases artefacts are simply listed by number 
and associated with the labourer who recovered or sold them; while in other instances the details recorded include the depth and location within the pit from which the artefact was recovered, either by one of the labourers or by Bean himself.

Two of the commonest descriptions of artefact depth are the ' 1 st floor level' and the 'datum level' (there are several references to apparently unrolled material from the levels at, or immediately below, the site datum). Both the datum level and the $1^{\text {st }}$ floor are clearly marked on Bean's section sketches (Figure 4). Although the datum, a cottage threshold on the south side of Holditch Lane, which runs along the southern edge of Pratt's Old Pit (Figure 2), no longer exists, its height (approximately 49m OD) was reconstructed by Green (1988: 178). Following Green (1988), these levels and those artefact descriptions relating position to the datum form the basis of the analysis of the assemblage's vertical distribution through the Broom sediments.

Green (1988: 179) noted that the majority of the Palaeolithic artefacts with recorded levels were recovered from the Middle Beds, and were most common $(63 \%)$ in the iron-stained gravels (the so-called 'red beds'), which were the source of many of the isolated, individual specimens. The Bean archive suggests that a relatively concentrated collection of rolled and unrolled material was recovered during 1938 from deposits of the Middle Beds type, abutting the southern edge of the pit that runs parallel with Holditch Lane. In this area, referred to by Green (1988) as the '1938 Locality', the upper surface of the Lower Gravel was inclined towards the east and fell below its normal level of $c .47 .6 \mathrm{~m}$ OD, to approximately $45.5 \mathrm{~m}$ OD. Individual elements of the overlying Middle Beds dipped conformably with the surface of the Lower Gravel. In this area the Lower Gravel was overlain by a bed of compact sandy-clay (yellowish-white in colour) that contained bifaces, débitage flakes and large blocks of chert, all of which were in an apparently unrolled condition. This bed was overlain by a 'red bed' comprising approximately $0.6 \mathrm{~m}$ of heavily iron-stained gravel, with a coarse texture and open fabric. Bifaces and débitage flakes, both rolled and unrolled, were found in this bed, while the workmen reported that concentrations of up to 30 bifaces had been found there. 


\section{PATTERNS IN THE BIFACE ASSEMBLAGE}

977 bifaces were sampled in the current study, 767 from the C.E. Bean collection (held at The Dorset County Museum, Dorchester) and 210 from the collection at the Royal Albert Memorial Museum and Art Gallery, Exeter.

\section{Typology}

Examination of biface typology using the Wymer (1968: Fig. 26 \& 27) matrix indicated a highly diverse composition, with cordate/ovate (type $\mathrm{J} / \mathrm{K}: \mathrm{n}=272,27.8 \%$ ), cordate (type $\mathrm{J}: \mathrm{n}=183$, $18.7 \%$ ), and pointed (type $\mathrm{F}: \mathrm{n}=109,11.2 \%$ ) forms the most prevalent, and smaller proportions of sub-cordate/cordate (type $\mathrm{G} / \mathrm{J}: \mathrm{n}=75,7.7 \%$ ), pointed/sub-cordate (type $\mathrm{F} / \mathrm{G}$ : $n=69,7.1 \%$ ), ovate (type $K: n=65,6.7 \%$ ), sub-cordate/ovate (type $G / K: n=55,5.6 \%$ ) and subcordate (type G: $n=54,5.5 \%$ ) bifaces (Table 3a \& Figure 5). The outline shapes of Bean's types 3, 4, 5, 10 and 16 (Figure 3) display affinities with the majority of these Wymer types (absolute numbers and percentages in the list below were calculated from Bean's own documentation of his collection of 898 bifaces):

- Bean's type $3(n=76,8.5 \%)$ and Wymer's sub-cordate (type $G)$ biface

- Bean's type 4 ( $n=457,50.9 \%)$ and Wymer's cordate (type J) biface

- Bean's type 5 ( $n=65,7.2 \%)$ and Wymer's ovate (type K) biface

- Bean's type 10 ( $n=109,12.1 \%)$ and Wymer's sub-cordate (type $\mathrm{G}$ ) biface

- Bean's type 16 ( $n=62,6.9 \%)$ and Wymer's cordate (type J) biface

Overall, while direct correlation of the two schemes is rather impractical (see also Marshall's (2001: 79) division of the Bean categories into ovate, pointed, ficron, and other forms), the general patterns suggested are similar, with a dominance of cordates, ovates, and 'interim' pieces (i.e. cordates/ovates). There are also small numbers of other distinctive typological forms (Figure 5), including 25 ficrons (Wymer type M: 2.6\%), 26 cleavers (type $\mathrm{H}: 2.7 \%$ ) and 12 flat-butted cordates (type N: 1.2\%; the term is used here after Wymer (1968), and not in the specific context of Tyldesley's (1987) 'true' bout coupé handaxes and their strong later Middle Palaeolithic associations in Britain (White \& Jacobi 2002)). The key difference 
however concerns the absence of a single dominant type using the Wymer scheme, unlike the status of the 'lop-sided' ovates/cordates or amygdaloids in the Bean scheme (type 4).

\section{Morphology}

\section{ASYMMETRY}

In the current analysis bifaces were characterised as asymmetrical by the presence of macroscopic asymmetry in artefact planform, based upon a visual assessment of the proportions of the artefact lying either side of the long axis, from tip to butt (Figures $6 a$ \& 7). The characteristic macroscopic asymmetry followed Bean's earlier descriptions and illustrations (Figure 3: type 4), with an exaggerated convex edge on either the left or right lateral, opposed by either a straight edge (Figure 6a) or a less-exaggerated convex edge (Figure $7 b$ ). The 'bulge' created by the exaggerated convex edge was typically in the butt half (Figure $7 b$ ) or mid third (Figures 6a \& 7a) of the biface. Artefacts classified as 'symmetrical' were not therefore perfectly symmetrical, but did lack a visually distinctive asymmetry in planform as described above. This method contrasts with Machin et al. (2007), who statistically manipulated digital images to classify artefact symmetry and asymmetry. However, it is argued here that for artefact symmetry/asymmetry to be significant it must have been discernable to the knapper at the time of manufacture (rather than just to pixel detection routines), hence its classification by eye (see also McNabb \& Rivett 2007). This approach is therefore closer to that of McNabb et al. (2004: 658), who divided bifaces into equal thirds (tip, medial, base) and "mentally folded over" each third to determine whether the outline edges were symmetrical. Each third was 'folded' across a longitudinal bisector, either passing through the middle of the tip for clearly pointed/markedly convergent bifaces, or defined by half the artefact's width. Nonetheless for purposes of comparison FlipTest (@ Hardaker \& Dunn; Hardaker \& Dunn 2005) index of symmetry measures are included for a sample of 60 Broom bifaces, classified visually as 'symmetrical' $(n=30)$ and asymmetrical $(n=30)$ in this study (Table 4, Figure 8 \& captions for Figures $6 \&$ 7). These data indicate a clear distinction in the central tendencies of the two samples, which occur respectively in the 'high' and 'very 
low' symmetry categories suggested by Hardaker \& Dunn (2005), although there is overlap between the distributions of the samples.

Under our methodology asymmetrical types comprised $23.7 \%(n=232)$ of the sample, suggesting that while these artefacts form a significant element of the Broom assemblage they are not as dominant as previously claimed by Bean (type 4: 50.9\%). These asymmetrical planforms occur on all of the principle Wymer types at Broom (although not on cleavers or flat-butted cordates), indicating that asymmetry was not exclusively associated with a single biface type. As with the total assemblage, the largest proportions of asymmetrical bifaces fell into the cordate/ovate $(n=98,42.2 \%$ of all asymmetrical bifaces) and cordate $(n=50,21.6 \%)$ types (Table 3a \& Figure 9). The individual 'oval' biface types (e.g. cordates and ovates) were also characterised by greater numbers of asymmetrical artefacts than the more 'pointed' forms (e.g. points and sub-cordates), ranging from $11.0 \%$ (points) to $35.3 \%$ (cordate/ovates; Figure 9). Initial comparison with selected other British assemblages (Table 1 \& Figure 1) indicates that Broom falls between Boxgrove and Bowman's Lodge, Corfe Mullen and Cuxton, and does not appear especially unusual in its degree of bifacial planform asymmetry. However the asymmetrical samples at Cuxton in particular (Marshall et al. 2002; Shaw \& White 2003), and to some extent at Corfe Mullen (Calkin \& Green 1949; Roe 2001; Marshall et al. 2002), include highly irregular forms, such as the long, narrow and thick Cuxton handaxes, with strongly wedge-shaped cross-sections, which reflect the 'burrow or pipe flint' nodules on which they were made (Shaw \& White 2003: 310). When only the 'lop-sided' element is included for these other sites, Broom exceeds Boxgrove and Corfe Mullen, and is comparable with both Cuxton and the much smaller assemblage from Bowman's Lodge. In summary what distinguishes Broom in terms of the symmetry issue is both the proportion of asymmetrical bifaces and the apparent imposition of a 'lop-sided' asymmetrical planform onto 'standard' or classic types (after Ashton \& McNabb 1994).

\section{PLANO-CONVEXITY}

There is also a significant element of the overall assemblage that is plano-convex in profile ( $n=204,20.9 \%)$, although there are no preferential associations with either individual Wymer 
types (Figure 10) or the asymmetrical component. Following the patterns seen in the overall assemblage, the plano-convex bifaces are numerically dominated by cordate/ovate $(n=61$, $29.9 \%$ of all plano-convex bifaces) and cordate $(n=35,17.2 \%)$ types (Table 3a), while 43 artefacts $(21.1 \%)$ in the plano-convex sample are asymmetrical in planform. The planoconvex sub-sample also mirrors the overall typological diversity of the assemblage, with the profile also evident on cleavers, ficrons and flat-butted cordates, inevitably in small numbers.

\section{Raw Materials}

The majority of the biface sample was produced in chert $(n=921,94.3 \%)$, with a small number of flint artefacts $(n=55,5.6 \%)$ and a single example made from quartzite. The chert was subdivided on the basis of gross visual characteristics and experimental knapping by Chambers (JCC) into fine-, medium- and coarse-grained chert. Medium-grained material was most frequently used $(n=474,48.5 \%$ of the total sample), followed by fine-grained ( $n=269,27.5 \%)$ and coarse-grained $(n=178,18.2 \%)$ cherts. Marshall (2001: 78) has previously noted the occurrence of large, lightly rolled chert blocks up to $35 \mathrm{~cm}$ in length within the Axe gravels, while flint occurred at low densities with only rare examples measuring up to $12 \mathrm{~cm}$ in diameter and the majority much smaller. Marshall (ibid.) observed that the flint was grainy and frost-fractured, and estimated that those large enough for biface manufacture comprised less than $5 \%$ of the deposit he examined at the Chard Junction pit. Edwards \& Gallois (2004: 17) describe the clasts of the Axe valley terrace deposits, predominantly Upper Greensand chert, as angular, while noting that some chert clasts in the Sidmouth District's head deposits reach $0.4 \mathrm{~m}$ or more in diameter (ibid: 15$)$. Shakesby \& Stephens (1984: 79) similarly noted that the breaking up of the chert bands within the Chert Beds produced angular material, some of which had moved downslope as a head deposit. Woodward \& Ussher (1911) describe the 'valley gravel' near Axminster station (c. 5km south of Broom) as consisting for the most part of 'rough flint and chert stones', while Salter (1898: 282) noted large blocks of chert up to 8" $\mathrm{x}$ 10" (i.e. c. $20 \times 25 \mathrm{~cm}$ ), in the gravel at Kilmington, c. $2 \mathrm{~km}$ west of Axminster. JCC's experimental work sampled raw materials from the fluvial deposits of the River Axe exposed at Chard Junction Pit. The experiments highlighted the problematic nature of the river gravel chert materials to a modern knapper primarily experienced in working flint: individual nodules 
were highly inconsistent in grain size and knapping properties. Both their dimensions and flaking properties did not favour flake blank production, and all experimental biface production was conducted through nodule reduction (façonnage). In summary the locally available chert materials can be characterised as angular blocks, reaching at least $25-40 \mathrm{~cm}$ in maximum dimension (Figure 11), with inconsistent granular and flaking properties, while the river gravel flint was relatively scarce, with poor flaking qualities, and small in size.

The proportions of the major artefact forms (points, sub-cordates, cordates, cordates/ovates and ovates) produced from the different raw material types showed no significant differences to the overall proportions for the assemblage (Table 3a \& Figure 12). The data therefore do not indicate the selective use of different raw material types to produce different biface forms (e.g. Figures $6 b \& 6 c)$. The proportions of asymmetrical and plano-convex artefacts (Figure 12) and other distinctive biface types (cleavers, ficrons and flat-butted cordates) produced in each raw material category were also generally similar to the overall sample. Biface dimensions across the raw material categories indicate that the flint artefacts were the smallest in length, breadth and thickness on average (Table 5). However the differences are relatively small (e.g. the average flint biface length is $86.6 \%$ of the average coarse-grained chert biface length), and the standard deviation values indicate comparable levels of biface size variability across all the materials (Table 5). These metrics and the small proportions of flint bifaces in the overall assemblage suggest that immediately available Axe valley floodplain flints were predominantly used by the hominins, and that only the larger of these flints were regularly selected for biface production, while the Chalk sources of larger flints (Newberry 2002) within 5-10km of Broom at Membury and Kilmington (Figure 1) were only rarely, if ever, exploited.

There was limited evidence of significant relationships between raw material type and the degree of biface refinement as measured by cortex percentage and the number of flake scars greater than $10 \mathrm{~mm}$ in any dimension (Table 5). Most notably, the average number of flake scars per biface (standardised according to biface length) increased from coarse-grained chert $(0.219)$ to flint $(0.315)$, suggesting that the finer-grained materials did facilitate more 
intensive flaking strategies (in real terms the flint bifaces contained 8 more flake scars on average than the coarse-grained chert examples). However there was no clear evidence for a raw material quality/biface refinement relationship with regards to the quantity of remaining cortex. Average cortex percentage values ranged from 7.0\% (medium-grained chert) to $9.7 \%$ (fine-grained chert), and there was no clear linear relationship between increasing amounts of remnant cortex and increasingly coarse-grained raw material. Analysis of Roe's (1968) proxies for biface refinement (in cross-section, measured by thickness/breadth, for all bifaces and for ovates only, and in the tip, for points only, measured by thickness $\mathrm{f}_{1} /$ length) also indicated no significant differences between raw material types. Cross-section values for all bifaces actually showed small increases (i.e. reduced refinement) from the cherts (0.397) through to the flint $(0.421)$, while the equivalent values for the ovate sample clustered around 0.400 (ranging between 0.392 for fine-grained chert and 0.402 for flint). The tip refinement values for points were very similar, ranging between $0.149-0.151$.

\section{Technological Attributes}

\section{BLANK FORMS}

Identifying the blank forms used in biface production was difficult, with diagnostic features such as flake butts, percussion bulbs, bifacial cortex, tabular cortex and cobble cortex frequently not surviving the process of turning a blank into a biface (blank form was unidentifiable in $590,60.4 \%$, of cases). In those cases where a positive identification was possible, flakes (including side-struck flakes) were the dominant blank type ( $n=220,56.8 \%$ of the positively identified sample, $n=387$ ), although there was also a significant number of cobbles $(n=94,24.3 \%$ - these values increase to $n=149,38.5 \%$, if naturally fractured cobbles and flaked cobbles are added). Flake blanks were produced on all raw material categories (Table 5), further indicating that the Broom hominins, unlike ourselves, were not hindered in their flaking strategies by the granular quantities of the different materials. The proportions do however suggest that flake blanks were less frequently produced on flint, most probably reflecting the smaller sizes of the locally-available materials in the river gravels. 
There were no distinct associations between blank form and cleaver, ficron or flat-butted cordate biface types, or between blank form and tranchet flake removals. The assemblage's major biface types did however demonstrate a significant association $\left(X^{2}=20.83, p>0.001\right)$ with respect to blank form (Figure 13). Points showed little preference (where the blank form could be identified) for production on either cobbles or flakes (cobbles: $n=26,52.0 \%$; flakes: $\mathrm{n}=24,48.0 \%$ ), while sub-cordates, cordates, cordate/ovates, and ovates all showed a preference for production on flakes (sub-cordates: $n=18,78.3 \%$; cordates: $n=35 ; 74.5 \%$; cordate/ovates: $n=64,81.0 \%$; ovates: $n=17 ; 100.0 \%$ ). Given the difficulty of blank form identification and the resulting small sample sizes, caution is advisable with the interrogation of this pattern, but the highest proportion of flake use is associated with ovate forms, suggesting parallels with the conclusions of White (1998a). While the reconstruction of blank shape at Broom is also difficult, refinement and cross-sectional uniformity measures are used here (after White 1998a: 18; Shaw \& White 2003). The metrical data for the principal biface types (points, sub-cordates, cordates, and ovates: Table 6) reveal a notable contrast between points (thicker, with a tapering cross-section) and sub-cordates/cordates/ovates (thinner, with a less tapering cross-section: the ovate (Wymer type $\mathrm{K}$ ) values for both categories are comparable to White's (1998: Table 3) Boxgrove data). Working on the assumption that biface shape reflects, at least in part, initial blank shape (supported by the differential quantities of remnant cortex: Table 6), these values suggest that the diverse range of biface shapes at Broom occurred partly in response to blank morphology, with the more regular production of points on thicker, wedge-shaped cobbles, and the preferential production of cordates and ovates on thinner, lenticular profile flakes.

Moreover there was a clear, significant association $\left(X^{2}=20.49, p>0.001\right)$ between blank form and the presence of plano-convex biface profiles: $75.9 \%(n=88)$ of plano-convex bifaces were produced on flake blanks, with the remaining $24.1 \%(n=28)$ produced on a mixture of cobbles, nodules, and tabular pieces (blank form was unidentifiable for a further 85 plano-convex bifaces). It would appear that plano-convex bifaces were more commonly produced through exploitation of pre-existing dorsal/ventral face profiles on the flake blanks, rather than through 
imposition of the form onto other blank types, although the strategy was not inevitable: a further 132 flake blanks were not knapped into plano-convex bifaces.

Despite the differential associations between blank form/shape and specific Wymer types/plano-convex profiles, comparison of a range of metrical and technological traits (after Roe 1968; Shaw \& White 2003) for the flake blank and cobble blank biface samples (Table 7) reveals broad similarities. Elongation (breadth/length), metrical refinement (thickness/breadth) and cross-sectional uniformity (tip thickness/butt thickness) values suggest that both groups of bifaces were non-elongated, relatively thin (comparable for example to Boxgrove and Bowman's Lodge; White 1998a: Table 3) and lacking an extreme tapering in cross-section (cf. Cuxton: Shaw \& White 2003: 310), although the flake blank bifaces were slightly more refined and uniform in cross-section, the latter probably reflecting the cross-sectional morphologies of the blanks. The average number of flake scars (standardised for biface length) are also comparable for flake and cobble blanks (Table 7). While there are notable differences between the cortical data these most likely relate to a combination of blank morphology (with no possibility of cortex on the ventral surface of the flake blanks) and a lack of concern with completely removing remnant cortex from cobble-made bifaces (Table 7; see also the cortex data for pointed bifaces in Table 6). These broad similarities may reflect the angular, 'blocky' nature of the predominantly-used chert raw materials, in contrast for example with the highly irregular Chalk flint nodules seen at Cuxton (Marshall et al. 2002; Shaw \& White 2003), and a consequent narrowing of the morphological variations between flake and cobble blanks, reducing their differential impacts upon flaking strategies. Overall these data suggest that the use of either flake and cobble blanks did not 'dictate' or constrain the hominins in terms of the general knapping strategies and morphological preferences which they utilised, although at the level of the individual reduction sequence specific blank shape was an influencing factor, resulting in a diverse range of final shapes (Table 6; Shaw \& White 2003: 311).

The majority of the asymmetrical bifaces were also produced from flake blanks (Figure 13), with flake blanks $(n=57 ; 72.2 \%$ of the asymmetrical sample where blank form can be positively identified) more dominant than in the overall biface assemblage. While there is a 
significant association between the use of blank forms and the imposition of an asymmetrical planform $\left(X^{2}=10.15, p>0.005\right)$ it is equally clear that a large number of flake blanks are not modified in this manner ( $n=163,74.1 \%$ of the flake blank sample): the association is again not rigid or inevitable. Moreover it is not the case that all ovate and cordate bifaces (or indeed any other Wymer types) produced on flake blanks had an asymmetrical planform imposed upon them: i.e. there is not a multivariate association between particular biface typologies, blank form, and planform asymmetry. Finally, C.E. Bean previously suggested that the swelling on the side of the asymmetrical forms generally contained a platform or the site of a knapping platform and drew parallels with the side-struck flakes of the Victoria West tradition. However the current analysis only identified a very small number of side-struck flakes $(n=15,3.9 \%$ of the positively identified blank form sample), of which just 5 (33.3\% of the side-struck flake sample) were modified into asymmetrical biface forms. Bean's suggestion does not therefore appear to explain the prevalence of asymmetrical bifaces in the Broom assemblage.

Despite the preferential association between asymmetrical forms and flake blanks, comparison of metrical data from these two samples (Table 7) indicates that the flake blank bifaces were on average lighter, shorter, narrower and thinner than the asymmetrical bifaces. Taking final biface dimensions as a proxy for minimum blank size, this raises the possibility that only flakes above a certain size were strongly preferred for producing asymmetrical bifaces on. This is supported by metrical data for those flake blanks knapped into asymmetrical bifaces, although the values still fall below the average metrics for the asymmetrical sample as a whole. As the metrical data for the asymmetrical bifaces made on cobbles also indicate the use of larger-than-average blanks (Table 7), is it the case that the asymmetrical biface was the preferred form at Broom, and that only limitations in available blank form size, both of flakes and cobbles, prevented it from being more widespread in the assemblage? However the remaining metrics data fail to support this notion, as standard deviation values (Table 7) indicate a comparable size range in both the asymmetrical and 'symmetrical' bifaces: there was not a habitual conversion of large blanks into asymmetrical forms, and such forms were also made on much smaller pieces. 
Comparison of further metrical and technological traits for the asymmetrical and 'symmetrical' biface samples (Table 7) again reveals persistent similarities. The elongation, refinement and cross-sectional uniformity measures indicate non-elongated, relatively thin bifaces lacking an extremely tapered cross-section in both groups. In short these data suggest that the general morphologies of the asymmetrical and 'symmetrical' bifaces were comparable, and given the similarities of the relevant measures to those for the flake and cobble blank bifaces (Table 7), that the asymmetrical planform was neither preferentially facilitated, nor restricted, by blank shape.

\section{TIP WORKING}

Biface tips were dominated by irregular rounded $(44.9 \%, n=439)$, rounded $(14.8 \%, n=145)$ and ogee $(10.0 \%, \mathrm{n}=98)$ points, reflecting the dominance of cordate/ovate and cordate types in the assemblage (Table 3b). Field and flume-based experimental work (Chambers 2005a, 2005b) has observed that biface tips are vulnerable to damage and potential modification during fluvial transport. The analysis of tip type patterning in this archaeological assemblage is therefore restricted to robust trends. However, it is noticeable that there is only a small presence of tranchet tips $(5.5 \%, n=53)$ in the assemblage. This is in contrast to Roe (1968: Table VI) and Marshall et al. (2002) who respectively recorded $34 \%$ and $23 \%$ of tranchet finishes on their differently sized samples $(n=172$ and $n=253)$ from the British Museum. The reasons for this discrepancy are unclear. While they may partly reflect the application of stricter criteria for tranchet finishes by the current authors, influenced by the 'classical' examples of tranchet evident at Boxgrove in the 1980s and 1990s (Roberts \& Parfitt 1999), a further possibility is the selective acquisition of tranchet-finished material for the collections which make up the British Museum sample. This latter point is potentially also supported by discrepancies in the metrical measurements between the British Museum collections and the Broom and Exeter samples (see Hosfield et al. forthcoming).

There are examples in the Broom and Exeter collections where the application of tranchet finishing has clearly resulted in the creation of an asymmetrical form through the removal of a large tranchet flake from the tip, down one margin of the artefact (Figure 7b), suggesting 
parallels with White (2006), Ashton $(2001,2008)$ and McPherron $(1995,2006)$. However it is also clear that the majority of asymmetrical forms $(n=216,93.1 \%)$ are not associated with tranchet working. Moreover of the 53 examples of tranchet, only $16(30.2 \%)$ are associated with asymmetrical forms: in other words an asymmetrical Broom biface was not an inevitable consequence of tranchet working, and indeed was very frequently created by other means. Such 'other means' might of course include non-diagnostic (i.e. non-tranchet) re-sharpening. However examination of the metrical data (after Roe 1968) indicates that the 'symmetrical' bifaces were on average lighter, shorter and narrower than the asymmetrical component (which, along with the tranchet finished element, comprised the largest pieces in the assemblage: Table 7). There was also little difference between the average number of flake scars (standardised for length) larger than $10 \mathrm{~mm}$ on the asymmetrical (0.243) and 'symmetrical' (0.256) bifaces. These data argue against 'uni-marginal re-sharpening' as a primary explanation for the asymmetrical bifaces, as well as limiting the possibility that initially larger asymmetrical pieces were re-sharpened into smaller 'symmetrical' forms.

\section{BUTT WORKING}

Biface butt forms were dominated by trimmed flat $(n=531,54.4 \%)$ and trimmed $(n=201$, 20.6\%) types (Table 3b), suggesting a preference for circumferential cutting edges which corresponds with the dominance of ovates, cordates and cordate/ovates in the assemblage (White 1998a). However there was also a significant presence of natural $(n=98,10.0 \%)$ and part trimmed/part cortical $(n=121,12.4 \%)$ types, suggesting diverse approaches to knapping of the biface butt, either extensive flaking (the dominant technique) or minimal working. These different approaches also cross-cut the biface type categories (Table 3b), although, unsurprisingly in light of the biface type/blank form association demonstrated above, there is a reduction in the proportion of trimmed/trimmed flat butts from ovates $(90.8 \%)$ to points $(63.3 \%)$

\section{EDGE PROFILES}

Biface edge types were dominated by sinuous and straight edges (Table 3b). The most dominant pattern was a pair (each biface was assigned two classifications, for the left and right margins of the piece) of straight edges ( $n=455,46.6 \%)$, with secondary amounts of one 
straight and one sinuous edge $(n=266,27.2 \%)$ and two sinuous edges $(n=212,21.7 \%)$. This overall distribution of edge profiles is generally replicated within the sub-sample of asymmetrical bifaces, suggesting that there were few differences in the techniques and traditions of production relating to edge profiles as applied to those pieces. There were very few examples of S-twist profiles, either on both edges of a biface or just one edge (3.8\%, $\mathrm{n}=37$, although this is again a lower figure than that suggested by Roe (1968: Table VI) and Marshall et al. (2002) of $12 \%$ and $17 \%$ for their differently sized British Museum samples). The cause of this discrepancy is, like the tranchet issue, unclear; although it may again relate to the selective acquisition of particular biface forms within the collections which make up the British Museum sample (Hosfield et al. forthcoming). Moreover, in many cases the S-twists are not pronounced, and in no examples were they as diagnostic as the $\mathrm{S}$ and Z-twisted ovates discussed by White (1998b). For all examples of the S-twist profiles there was no suggestion of their selective production in particular raw materials, with medium-grained chert $(59.5 \%, n=22)$ dominant, and smaller amounts of the other materials: fine-grained chert $(29.7 \%, n=11)$, coarse-grained chert $(5.4 \%, n=2)$, and flint $(5.4 \%, n=2)$, broadly replicating the raw material proportions in the entire assemblage. With respect to the potential influence of blank forms upon edge profiles (particularly S-twist profiles), the sample was unfortunately too small to draw any clear patterns. However, there was apparently no relationship between sinuous edge profiles and the use of cobble blanks. Rather, the ratio of cobble: flake blanks for bifaces with sinuous profiles (1:1.7) was similar to that for the entire assemblage (1:1.5), suggesting that there was not a premeditated selection of cobbles for rapid, on-the-spot production of 'crude', relatively unrefined bifaces, as measured by the presence of a sinuous edge profile. Overall the data suggested that biface type, shape, and blank type did not significantly affect edge form.

In summary, the analysis of the Broom bifaces suggested:

- Typological diversity, including distinctive forms such as cleavers and ficrons, with a general preference for cordates and ovates, and varied approaches to tip, butt, and edge working. 
- Planform asymmetry occurs across the principal biface types, and is associated with larger-than-average bifaces, although there is general morphological similarity with the 'symmetrical' examples in terms of elongation, refinement and cross-sectional profile.

- No evidence for raw material type and/or granular quality impacting upon biface production (as represented in typology, metrics and refinement), with the exception of the flint sources, where the generally smaller size of the material effected biface metrics and the frequency of flake blank production.

- Blank form and shape influenced the proportions of the major biface types (White 1998a) and biface morphology (plano-convexity and asymmetry), although the general morphological characteristics of bifaces made on flakes and cobbles were similar, and the associations (e.g. between flake blanks and asymmetrical forms) were not rigid.

- Asymmetrical planforms were sometimes created by large tranchet removals, although significant numbers of artefacts could not be explained in these terms, or by reference to 'generic' re-sharpening and reduction intensity (cf. McPherron 1995, 2006).

\section{VARIABILITY THROUGH THE BROOM SEQUENCE?}

The records of C.E. Bean indicate that bifaces were recovered from depths within Pratt's Old Pit which potentially relate to all three of the sedimentary units at Broom, although the majority were clearly associated with the Middle Beds. However although the recorded heights indicate artefacts recovered from between 25' above and 10' below the site datum, it is clear from detailed analysis of Bean's archive that not only were the majority of the artefacts from the Middle Beds (i.e. around the datum level), but also that a significant proportion of the overall assemblage were acquired from the '1938 Locality' (Green 1988) in the south-eastern corner of Pratt's Old Pit where the Middle Beds dipped by up to $c .2 \mathrm{~m}$. In short, the overwhelming majority of the Broom artefacts appear to have originated from the Middle Beds (if not always from the datum level), and that the recorded artefact heights in the Bean archive cannot always be taken as a reliable indicator of the sedimentary unit from which the material came (cf. Hosfield 2005). This is especially true as Bean's field notes often recorded the vertical but not lateral positions of artefacts, and sometimes vice-versa. 
Nonetheless there does appear to be a genuine presence of artefacts in the Upper Gravels, both according to Bean's archive and Moir's (1936) observations, although Moir's account was clearly much influenced by Bean. A key question therefore concerns whether the two units, and their contained artefacts, are chronologically distinct? The OSL dates for the Broom sediments sampled from Pratt's New Pit and the Railway Ballast Pit (Table 2; Toms et al. 2005) do not provide an absolute geochronology for the intervals between the two dated units, but Bayesian modelling of the samples has suggested a potential chronological break, with age intervals of mid MIS- 9 to mid MIS- 8 for the Middle Beds, and MIS- 8 to MIS- 7 for the Upper Gravels. However while the sedimentary evidence documents a sharp boundary between the Middle Beds and the undated Lower Gravels, there is not a clear interface between the Middle Beds and Upper Gravels. Two contrasting models for the incorporation of the artefacts within the upper two units of Broom sediments therefore require consideration:

- Model 1: Over at least two chronologically distinct events, artefacts were discarded onto the Axe floodplain during occupation phases and rapidly incorporated into the accreting fluvial sediments at Broom - respectively the Middle Beds (earlier phase(s)) and the Upper Gravels (later phase(s)). Therefore the two groups of artefacts are broadly contemporary with their different sedimentary contexts, and are not contemporary with each other.

- Model 2: Artefacts were primarily discarded onto the floodplain during a single phase of hominin activity that post-dated the formation of the Lower Gravels and either pre-dated or was broadly contemporary with the formation of the lower energy Middle Beds. These artefacts were subsequently partly or wholly buried within the floodplain and channel deposits characteristic of the Middle Beds. Subsequent migration of the River Axe across its floodplain led to the gradual erosion of selected artefacts, re-working by the fluvial system and their gradual re-deposition within the later parts of the accreting sedimentary sequence (the Upper Gravels) - i.e. not all of the artefacts are contemporary with their final sedimentary contexts, but were originally contemporary with each other. 
The first model finds support in the potential chronological interval between the middle and upper units as indicated by the OSL dating and Bayesian modelling. The documented presence of flakes as well as bifaces in the Upper Gravels is perhaps also noteworthy as such material is likely to have been less resistant to the re-working proposed in model two. The potentially problematic nature of current OSL dating at and beyond a quarter of a million years ago is acknowledged, demonstrated for example by Briant et al.'s (2006: Fig. 4) wideranging age estimates for the Tom's Down Gravel and Old Milton Gravel in the Solent River system (but see also Briant et al. 2009: 167-168), although with regard to the Broom dating it is important to re-state that:

"...the accuracy of the raw optical chronology can be substantiated intrinsically by the convergent age estimates from stratigraphically equivalent units of divergent dosimetry. Bayesian analysis indicates sample age estimates for the major units (Middle Beds, Upper Gravels) are consistent with their relative stratigraphic position and is further testament to the accuracy of the optical chronology."

Nonetheless the single-proxy nature of the Broom dating does recommend its cautious use as a support for the first model, as does the sedimentary evidence for a gradational rather than sharp boundary between the middle and upper units.

Support for the second model derives principally from the concentrated association of the majority of the Broom artefacts (bifaces, cores, and flakes) with the Middle Beds levels, as documented in Bean's archive both through his own observations and from his discussions with the gravel pit workers. References to 'sharp' and 'fresh' flakes and 'chips' from these levels supports either the presence of in situ occupation surfaces (as argued by Moir 1936) or perhaps very locally re-worked artefacts, although the physical condition of the bifaces and other comments in the Bean archive suggests that at least some of the material in the Middle Beds had undergone greater degrees of fluvial re-working. The association of the majority of the artefacts with the Middle Beds is also supported, to a lesser extent, by the more sporadic 
documentation of the Railway Ballast Pit collections. Salter (1898: 282) emphasised the presence of abundant chert implements "mostly in the bottom layers", while Woodward \& Ussher (1911: 75) describe gravel and sand being worked to a depth of more than $35^{\prime}$. Based on modern surface elevations both within and to the immediate east of the Ballast Pit (Figure 2), this would suggest that Salter's 'bottom layers' were at the elevation of the Middle Beds. Moir (1936) also argued that most of the 'rolled' artefacts occurred in the Upper Gravels, supporting the re-working element of model two, although the current analysis did not detect notable contrasts in the degree of biface abrasion between the Middle Beds and the Upper Gravels.

Therefore while unequivocal support for either model is lacking, the preferred interpretation is model two, given the apparent concentrations of bifaces, flakes and cores in the Middle Beds (Green \& Hosfield forthcoming), and the limitations and contradictions in the sedimentary and dating evidence. It is emphasised however that localised re-working of the majority of the artefacts into the Middle Beds, rather than a fully in situ setting (cf. Moir 1936), is preferred in light of the physical condition of the artefacts. Furthermore it is possible that a small proportion of the Broom artefacts may represent hominin activity in early and/or later phases unconnected with the period of the Middle Beds' formation, although it is not possible to unequivocally demonstrate this.

In light of this geochronological and geoarchaeological framework, it is perhaps unsurprising that a comparison of selected typological and technological biface characteristics from the Middle Beds and the Upper Gravels indicates little significant variation, either from each other, or the overall assemblage pattern (Table 8; although the potential problems of small sample sizes is fully acknowledged). Indeed the limited variability between the samples is arguably a further piece of evidence in support of model two's proposal that the Upper Gravel material was re-worked from the underlying Middle Beds. Smaller artefacts (measured by weight) were more common in the Middle Beds sample; however this may reflect taphonomic processes, principally stream competence. 


\section{DISCUSSION}

The Broom bifaces encompass a wide range of types and a highly distinctive asymmetrical element, and are produced in chert and, to a small degree, flint raw materials, with the chert characterised by relatively large angular blocks and showing considerable variability in its granular consistency and flaking quality. Analysis of the artefacts indicates an absence of significant relationships between biface types and (i) the presence/absence of asymmetry, (ii) raw material type and granular quality, and (iii) plano-convexity and edge profiles; and between biface refinement and raw materials, using metrics and flake scar and cortical proxies. However the analysis did indicate significant associations between blank form and (i) biface types, (ii) the presence/absence of asymmetrical planforms, and (iii) the presence/absence of plano-convex profiles. These data suggest a series of conclusions with regards to hominin biface production and technological behaviour at Broom.

\section{Raw Materials \& Blanks}

Within the range of raw materials exploited at Broom (flints and variable quality cherts) there was no clear evidence for strong, influencing factors upon biface refinement, for example, between raw material granular qualities (fine to coarse-grained) and the degree of biface refinement (measured by the number of flake scars, the percentage of unremoved cortex, and Roe's (1968) metrical proxies for cross-section and tip refinement). While fine and mediumgrained cherts were predominantly utilised for biface production, there were no notable associations between the type and granular quality of the raw material and the types of bifaces produced (dominated across all material types by cordates and cordate/ovates), the balance of flake: cobble blanks, or the presence/absence of planform asymmetry. There were also no preferential associations between the relatively rare S-twist profiles and differing raw material qualities. The Broom raw material data therefore provides, albeit over a much narrower range of raw material variability and with reference to a mixed flake/cobble blank assemblage, some support for Sharon's (2008: 1329) observation that "raw material constraints did not significantly affect either the blank production process or large cutting tool shape and size variability". 
The prevalence of chert in the Broom assemblage, combined with the relatively large size of the available materials in the form of angular blocks, strongly supports the immediate use of local chert nodules from the Axe floodplain. Alongside the dominant chert component, the proportion of flint in the biface assemblage $(5.6 \%)$ and the flint biface metrics are also suggestive of the use of local materials, most probably from the Axe gravels (Marshall 2001: 83), despite the relatively local availability of fresh Chalk sources at Beer, Furley/Membury, and Widworthy/Wilmington (Newberry 2002). Ashton (2001, 2008) has recently highlighted the potential role of raw material curation in the British Lower Palaeolithic, based around the economising of rare, good quality, raw materials through re-sharpening, with reference to distinctively plano-convex bifaces at Wolvercote (Ashton 2001, 2008), Boscombe, and Red Barns (Ashton 2008). In this context it is notable that the highest average flake scar counts adjusted for length $(0.315)$ occur on the flint bifaces, although the range of variability between the flint and coarse-grained chert values (Table 5) is relatively narrow (contrast for example with White 1998a: Table 3). However, while the proportion and sizes of immediately available flint at Broom might suggest the need for economising, the quality and refinement of elements of the chert biface component, combined with the local presence of large chert blocks, suggest that such re-sharpening strategies were not a significant or required element of the Broom assemblage. This is further supported by the proportion of tranchet flakes occurring on the flint bifaces $(n=4,7.3 \%)$, and the proportion of plano-convex forms occurring in flint $(n=11$, $20.0 \%$ ), both of which are comparable to the tranchet/plano-convex proportions across the entire assemblage (respectively $5.4 \%$ and $20.9 \%$ ) and suggest that flint bifaces were treated little differently to the other raw materials used at Broom with regards to economising and curation.

However there is clear evidence of an association between flake blanks and the production of sub-cordates, cordates, cordate/ovates, and ovates, supporting White (1998a). The impact of blank morphology upon biface knapping decisions at Broom is also evident in the preferential association between flake blanks and plano-convex forms, with exploitation of the ventral surface as the 'planar' face. There was similarly a differential preference for relatively large flake blanks in the production of the asymmetrical forms, perhaps because such blanks 
provided, in White's (1998a: 22) phrase, "few restrictions to action", facilitating the knapping of the exaggerated convex profile or 'bulge' on one of the laterals. It is evident however that the relationships between blank type and biface form, particularly with reference to planoconvexity and asymmetry, are not rigid or exclusive. For example, $132(60.0 \%)$ and 163 (74.1\%) of the flake blanks transformed into bifaces did not adopt a plano-convex or asymmetrical form respectively, while $31(26.1 \%)$ of the plano-convex bifaces and $25(30.1 \%)$ of the asymmetrical bifaces were produced from cobbles, nodules and tabular pieces (the percentage figures are for those examples where blank form could be positively identified). These latter patterns perhaps reflect the 'blocky' and angular, rather than highly irregular, nature of the chert raw materials. There is also no evidence that asymmetrical forms were restricted to larger blanks, whether flakes or cobbles, although they are characterised by average metrical values at the upper end of the Broom range.

The overriding impression therefore is that the hominins at Broom were being very flexible in biface production with regards to the inter-changeable use of different raw materials or cherts with variable granular qualities to produce a wide range of typological and morphological forms. Blank form does appear to be a significant factor with regards to biface shape, with the observed associations broadly following White (1998a), although the broadly similar metrical and technological 'character states' of the flake and cobble blank components (Table 7; after Shaw \& White 2003: 311) suggest that in all cases the materials used "elicited a similar suite of technological responses". The bifaces' final (typological) shapes therefore appear to have emerged from the interactions between case-by-case variations in blank shape and a knapper's skills, preferences and choices (ibid.). This conclusion is further supported by the similarities in the character states of the asymmetrical and 'symmetrical' bifaces: the impression is that these two groups of bifaces are distinguished 'only' by the presence or absence of a lateral bulge, and not by any other metrical or technological (as opposed to typological) criteria. Thus while blank form identification at Broom was frequently difficult and the sub-division of chert raw materials was visually-based, the evidence from the artefacts suggests that factors additional to these also played a significant role in influencing the character of the end projects of biface manufacture; these are discussed further below. It is 
also worth re-stating, with specific reference to Bean's Victoria West analogy, that there was no significant evidence for platforms on the 'lateral bulge' of the asymmetrical ('lop-sided') artefacts in the collections examined.

\section{Chronology}

If the relatively late Lower Palaeolithic OSL dates from the Broom sediments are accepted, the evident flexibility and diversity in biface production at the site (whatever its cause) and the presence of both ficrons and cleavers offers a perspective on Wenban-Smith's (2004: 17-20) recent claim for increasing varieties of distinct biface types as the British Lower Palaeolithic progresses. It is therefore interesting to revisit the geochronologies for the other assemblages characterised, like Broom, by Roe (1968) as 'intermediate': Santon Downham, Wallingford, and Barton Cliff (Figure 1). While Roe (1981: 154) himself acknowledged potential problems with assemblage integrity for all of his 'intermediate' sites (i.e. the apparent wide variety of types is due to the mixing of discrete assemblages), his description of the group is intriguing, referring to:

“...various pointed and ovate handaxe types (including extreme forms of each) occur apparently together in proportions outside the range of any Group attributed to either the Pointed or the Ovate Tradition. Pointed handaxes with twisted tips, fully twisted handaxes, and tranchet-finished handaxes all appear at each site. One or two cleavers also occur."

(Roe 1968: 78)

Roe (1968: 10) argues that the Barton artefacts may have originated from a relatively small area of gravel, capping the low sea cliffs, although Evans (1897: 637) provides a much more cautious interpretation of their origin, assigning their provenance to a stretch of coastline encompassing at least four Solent River terrace gravels (Briant et al. 2009: 161). Recent work on the Solent terraces (Bridgland 2001; Westaway et al. 2006; Briant et al. 2006, 2009) suggests that the Old Milton Gravel at Barton-on-Sea most likely dates to either the MIS11/10 transition (Bridgland 2001), MIS-10 (Westaway et al. 2006; Briant et al. 2006), or MIS11 to 9 (Briant et al. 2009). Although the Wallingford artefacts were recovered from a series of 
pits, Roe (1968: 22) noted that they do originate from a single deposit, albeit one seven miles in length and between one and four miles wide. Horton et al. (1981: 246-247) suggested that the Wallingford Fan Gravels, which accumulated by a mixture of solifluction and fluvial deposition, might be contemporaneous with the Upper Winter Hill terrace. Following Bridgland (1994) this would most likely place the Wallingford deposits in MIS-12, and this assignment is further supported by Wymer (1999: 175-176), who argued for an Anglian (MIS-12) date on the grounds that the chalky fan gravels grade into patches of the Upper Winter Hill terrace gravels. Wymer also suggested that the palaeoliths must have been derived off the slopes or crest of the Chilterns' chalk escarpment (ibid: 175). It is unfortunate that the exact origins of much of the Santon Downham material and the geochronology of the deposits have yet to be established, although Mark White's 1996 investigations did identify laminated lake clays, suggesting that the artefacts may be derived from a nearby lakeshore (Wymer 1999: 161).

Overall there is little evidence at the current time to argue that all of Roe's (1968) 'intermediate' group date to the late Lower Palaeolithic, while the integrity of the Barton, Wallingford and Santon Downton assemblages remains uncertain. While this comparison does not alter our view that Broom is characterised by a genuinely diverse biface assemblage resulting from hominin behaviours rather than fluvial mixing, it perhaps does reduce the possibility that all such highly diverse assemblages reflect a widespread late Acheulean approach to biface manufacture in Britain.

\section{Techniques and Traditions of Manufacture}

Within the geochronological resolution of the deposits and the assemblages, there is no evidence of significantly changing traditions over time: the full variety of Broom biface types occur throughout both the Middle Beds, predominantly, and the Upper Gravels. This can be most easily explained by assigning the majority of the Broom artefacts to a single occupation phase that was broadly contemporary with the formation of the Middle Beds (model two as outlined and supported above). Nonetheless what is notable is that asymmetry is not exclusively associated with either finer (or coarser)-grained raw materials or particular blank forms, but rather seems to be imposed during the production of a range of biface types from 
both flake and cobble blanks, albeit with a preference for flake blanks. It is not imposed on all bifaces of a specific type, although it is most prevalent amongst the cordate/ovates, but neither is it totally absent for any specific types. Finally the similar character states of the 'symmetrical' and asymmetrical bifaces (Table 7) would seem to suggest that the 'bulge' feature is not a fundamental part of the knapping process, in the sense of it not notably differentiating the values of those character states. While there are instances where the asymmetrical planform was most likely a product of tranchet flaking (Figure $7 \mathrm{~b}$ : compare with Roe 1981: Fig. $3.7(7 \& 8))$, there are a large number of cases where this is not the case (e.g. Figures $6 \mathrm{a} \& 7 \mathrm{a}$ ). This would seem to indicate that the distinctive asymmetry at Broom is not purely a product of dealing with a particular raw material or blank form, or of producing a particular 'type' or shape of biface, and that it is only partly a consequence of tranchet tip finishing and/or re-sharpening. Certainly intensive curation of bifaces, either in flint or chert, in response to raw material quality and availability in a flint-poor landscape (Ashton 2001, 2008) was apparently not a major part of the behavioural signature at Broom.

We therefore suggest that the Broom asymmetrical bifaces also reflect manufacturing choices which are, at least partially, unrelated to issues of raw material quality, blank form, biface type, or re-sharpening intensity. As to what these choices do represent we provisionally follow Shaw \& White (2003: 311) and Sharon (2008: 1342) in suggesting two possibilities for consideration here, both of which are linked beneath the umbrella of knapping traditions and preferences: (i) the 'style' or working traditions of a single individual or very small numbers of hominins over a very short period; and (ii) local/regional traditions of relatively short duration, operating at a group level.

The planform distinctiveness (and marked similarity in some cases: e.g. Figure 7) of the asymmetrical bifaces does raise the possibility that they are the products of an individual hominin's knapping skills, techniques, and preferences: essentially an idiosyncratic trait. This raises the question of how many hominins in any particular group were responsible for, or had access to the knowledge for, biface production, but certainly the numbers of those bifaces ( $c$. 250 in the examined sample, potentially up to $c .500$ for the entire Broom assemblage if a 
persistent ratio is assumed) does not preclude the possibility that it reflects the life's work (or less) of one or two individuals. An intriguing addition to this suggestion of 'personal idiosyncrasy' comes in the form of a flake scraper from Broom (British Museum 1933 4-6 2, Garraway-Rice collection), the planform of which is strongly reminiscent of those of the asymmetrical bifaces yet occurs on an artefact type probably used for different purposes (e.g. Keeley 1993).

At a micro-level of analysis there is also potential evidence for individual hominin knapping in the 'symmetrical' biface component, of the sort suggested for Foxhall Road, Ipswich and Boxgrove (Hopkinson \& White 2005: 23 \& Fig. 2.1; White \& Plunkett 2004: 105-110 \& 150; Pope et al. 2006: 51 \& Fig. 5). Bean's numbered recording system is problematic here, since he notes that numbers 1-113 are 'mixed', nonetheless the similarity in the form of bifaces 94 and 85 (Figures $6 b \& 6 c$ ) is intriguing. While the geoarchaeological context of these artefacts (in contrast to that at Foxhall Road and Boxgrove) limits the further development of this argument, it is notable that the same form (and general overall size) has been replicated on two different raw materials: fine-grained chert and flint. A further line of support from the Broom archive with regards to short-lived traditions concerns a temporal pattern in the bifaces recovered from Pratt's Old Pit between 1931 and 1941. The proportion of asymmetrical bifaces found relative to other forms rises notably after the end of 1937 , from $10.4 \%(n=41)$ to $33.3 \%(n=157)$. The majority of the post-1937 bifaces appear to have been recovered from the '1938 Locality', although the nature of the archive does not permit many of the individual artefacts to be precisely provenanced. Analysis of the sedimentary record has led Green (Green \& Hosfield forthcoming) to suggest that the '1938 Locality' may represent a localised deepening of the Axe Channel, perhaps a scour pool, into which bifaces were re-worked from the adjacent floodplain. This raises the possibility that the greater asymmetrical biface component in the post-1937 material reflects, at least partly, sustained discard if not also production of these distinctive bifaces in a localised area of the floodplain. While the chronology of their production/discard is harder to assess, the Bean archive's references to concentrations of bifaces ("found together", "in a heap"), combined with the generally lightly 
abraded conditions of the Broom bifaces, is at least suggestive of their accumulation over a relatively short period (Hosfield et al. forthcoming).

As stated above, the preferred interpretation of the formation of the Broom assemblage is that the bifaces were all produced during a relatively short-lived occupation in the Axe Valley, most probably lasting a handful of generations or less, using the biface numbers from the Boxgrove raised beach as a very broad comparison (Roberts \& Parfitt 1999). This permits both a 'group manufacturing tradition' explanation and the 'products of individuals' explanation, and also enables consideration of the 'user habits' of individuals. Observations by Pope during butchery experiments (Machin et al. 2007; Machin 2009: 41-42) have highlighted the potential importance of feedback mechanisms between technique of use and the morphology of a biface: i.e. what is made influences how it is used, while the preferred techniques of the user may influence what is made. While Machin and Pope both highlighted the importance of micro-scale variations in edge form, as opposed to the degree of planform symmetry, in terms of the butchery effectiveness of a biface (Machin et al. 2007: 891-892), the characteristic morphology of the asymmetrical Broom bifaces (opposing convex/straight edges or opposing convex/exaggerated convex edges) could be considered in terms of its prehensile properties. This is not in terms of a broader 'universal' functional advantage or efficiency, not least because of the association of the asymmetry with a diverse range of biface shapes (see also Winton 2004) and the proportions of such artefacts at both Broom and elsewhere, but with reference to the distinctive user preferences of individuals (Machin 2009: 41). Interestingly the two character states which reveal the greatest divergence between the 'symmetrical' and asymmetrical components concern the percentages of bifaces with all-round cutting edges (respectively $35.8 \%$ and $48.7 \%$ ) and of fully worked butts $(73.2 \%$ and $80.4 \%$ ), further supporting a prehensile-related explanation.

Moving out from the individual, claims for a local or regional tradition maintained at the group level is a familiar approach, reflecting an analytical unit that has been widely used in Palaeolithic studies (e.g. Mithen 1993). However a group-maintained tradition is perhaps somewhat at odds with the patterning in the asymmetrical bifaces. The evidently flexible and 
non-rigid associations of that planform across a variety of biface types, raw materials, blank forms and other technological strategies does not seem suggestive of the conservative material culture traits which are typically associated with vertical transmission and maintained group traditions (Hosfield 2009). Staying at the group level however, an alternative potential explanation of the Broom bifaces' diversity and the diverse imposition of asymmetry highlights weak social learning mechanisms (e.g. Mithen 1994, 1996) and/or a social acceptance of bifacial knapping diversity, stemming from weaker social groups: in effect, the observed patterning results from continuous variation in the implementation of the biface concept (see also Ashton \& McNabb 1994) as opposed to being the product of a distinct local or regional tradition. Following Mithen's (1996: 218) proposal that smaller social groups may be associated with diverse knapping procedures due to the absence or weaker influences of cultural traditions of artefact manufacture, the relative sparseness of the Lower Palaeolithic record in the south-west (Wymer 1999; Hosfield et al. 2006) provides some support for this interpretation, particularly with reference to the observed diversity of the Broom bifaces (although this is also partially explained through blank form variability). However the persistence and distinctiveness of the asymmetrical form, albeit probably over a single occupation phase, still requires explanation within such an interpretation.

The Broom assemblage is a combination of (i) a distinctive asymmetrical component, which cannot be fully explained with reference to 'production and use' factors such as raw materials, blank forms, and re-sharpening, occurring within a highly variable biface assemblage; and (ii) the context of a single occupation phase. The 'background' biface variability would appear to argue against a strongly maintained group-level tradition, and in favour of a set of variable and flexible approaches to biface production, by a relatively large number of individuals, reflecting the subtle interplay of individual skills, preferences, and choices, alongside the properties of the materials locally to hand (Shaw \& White 2003: 311; Machin 2009). Such variable and flexible approaches may also be a product of weak social learning mechanisms (Mithen 1994, 1996). The asymmetrical component is enigmatic, but its partial non-tethering to production and use variables, suggests the strong possibility of their being idiosyncratically produced by at most a handful of individuals. It is possible that production and use factors, in 
particular blank form, and artefact curation through re-sharpening, led to the initial appearance of the asymmetrical forms, but if this was the case, it is equally clear that their continued production occurs outside of those factors: the persistence of personal knapping styles and habits would appear to best explain that aspect of the artefact record.

\section{THE BROOM BIFACES IN CONTEXT}

As observed above, evaluation of the competing models for the formation of the Broom assemblage must overcome contradictory strands of evidence. However our favoured interpretation of a single phase occupation, with limited later re-working, is further supported when assessing the wider context of the material. If the production of asymmetrical bifaces at Broom was persistent across more than one occupation phase (as is required by the first of the geoarchaeological models presented) or was part of a wider regional tradition, then questions arise as to where the hominins go when not present at Broom, and how the production knowledge and tradition of these distinctive bifaces might have been maintained?

In a multi-phase occupation model the episodic production of asymmetrical bifaces would be most easily explained with reference to raw material properties and availability and/or functional requirements that acted at a local scale: in effect that the production of these bifaces was in response to environmental/habitat 'triggers' such as raw material economizing (Ashton 2001, 2008) that the hominins encountered at or near Broom. However the analysis of the biface variability suggests that while factors such as tranchet re-sharpening and the use of flake blanks appear to have played a partial role, they by no means fully explain the asymmetry. It is thus difficult to explain why or how new hominin groups sporadically arriving at Broom would produce such bifaces, unless they were descended from earlier 'Broom' populations and had retained the relevant traditions of biface manufacture through vertical transmission across generations, perhaps with parallels to White's (1998b) interpretation of twisted ovate handaxes during MIS-11. The maintenance of such ancestor/descendent connections, as opposed to their loss through local extinctions in response to Middle Pleistocene climatic cycles (e.g. White \& Schreve 2000), would almost certainly require considerable mobility however. While the available geochronological framework lacks 
precision, it is likely that the harshest of the early MIS-8 conditions and/or short-lived stadial oscillations in MIS-9 would necessitate wide-ranging hominin mobility (e.g. southwards into the Mediterranean), from which a specific return to Broom seems rather unlikely.

Within the generally milder interglacial conditions of MIS-9 it is however possible that successful mobility strategies could have operated on a regional scale. Adjacent archaeological landscapes to Broom include other areas of the south-west (e.g. the Bristol Avon (Lacaille 1954; Roe 1971) and/or the Vale of Taunton (e.g. Norman 2000; Figure 1), wider regions of southern Britain (e.g. the Thames or Solent River landscapes: Bridgland 1994; Wymer 1999; Wenban-Smith \& Hosfield 2001; Figure 1), and beyond into northwestern Europe (e.g. the Channel River and its southbank tributaries such as the Somme and the Seine: Antoine et al. 2003; Lericolais et al. 2003):

1. However there is certainly insufficient material in the south-western region of Britain to support a persistent occupation model that includes sporadic appearances at Broom (Hosfield et al. 2006), although it is possible that the distinctive formation of the fluvial archive in the south-west, combined with limited collection and sampling opportunities over the last 150 years, has mitigated against the long-term preservation and subsequent collection of an unknown quantity of artefacts and assemblages (Hosfield et al. 2007: Section 5).

2. Nonetheless it is also noticeable that neither the Bristol Avon nor the Vale of Taunton artefacts reveal a significant asymmetrical component (Lacaille 1954; Norman 2000, pers. comm.), although there are occasional examples (Norman 2000: Fig. 9.3(1)), and nor is it possible at the current time to demonstrate that these assemblages are even broadly contemporary with Broom.

Indeed in terms of a national picture there also do not appear to be sufficient numbers of asymmetrical bifaces in the British record for the MIS-9/early MIS-8 period (Roe 1968, 1981; Wymer 1999; McNabb 2007) to support a regionally persistent occupation characterised by the maintained production of these artefacts. Moreover this is a time period when eastern 
England is beginning to mark a technological shift towards Levallois technologies (White et al. 2006), and Britain in general is possibly undergoing widespread population decline (Ashton \& Lewis 2002), raising additional question marks over the possibility that asymmetrical bifaces of the Broom planform were persistently being produced by a mobile hominin population in Britain. Interestingly the very limited evidence for Levallois artefacts at Broom further supports the possibility that bifaces, including the asymmetrical element, are a local preference, in contrast to the prepared core technologies of the early Middle Palaeolithic (three Levallois artefacts are listed in the Southern Rivers volume for Broom (Wessex Archaeology 1993: 163), although the analysis of the Bean and Exeter collections identified no Levallois pieces, nor have these artefacts been seen elsewhere by the authors). There is also some wider support for this in the late MIS-8 biface assemblage from Harnham in Wiltshire (Whittaker et

al. 2004; Figure 1), while there is also the potential geographical semi-isolation of the southwest landscape through its distance from the headwaters of the Thames and the Solent River and their tributaries (e.g. the Frome, the Piddle, and the Kennet), and its southern bordering by either the English Channel or the wide expanses of the Channel River's floodplain.

In short, while interpretation of the Broom archive, artefacts, and dating is on occasions contradictory, our preferred interpretation favours a single occupation phase, whereby the asymmetrical bifaces are a local and short-lived tradition (possibly even the produce of a single individual or a small number of individuals within a larger group), following which the hominins either go locally extinct or abandon the area.

\section{CONCLUSIONS}

The fascination and significance of the Broom artefact assemblage unquestionably lies in the sheer diversity of biface manufacture that is evident, and in the distinctive asymmetrical component. Analysis of the artefact data suggest that both of these patterns are not the result of raw material conditioning, while the asymmetrical bifaces are only in part a consequence of blank form and re-sharpening strategies. Since the diversity of forms is seemingly not due to the mixing of multiple distinctive samples within the Broom fluvial sediments, support is given to the presence of micro-traditions in knapping (the asymmetrical component), set against a 
background of highly flexible and variable implementation of the 'handaxe concept' (Ashton \& McNabb 1994). Whether these micro-traditions belonged to single individuals/generations or were passed down across a small number of generations is unresolvable, but the favoured geoarchaeological model and the sparse regional archaeological context supports their being associated with a small number of knappers, present at Broom during a relatively short phase of continuous local occupation that lasted a few generations at most.

\section{ACKNOWLEDGEMENTS}

The work reported here was funded through the Aggregates Levy Sustainability Fund (English Heritage), as part of The Archaeological Potential of Secondary Contexts project (No. 3361), whose further financial support of the paper's publication is also gratefully acknowledged. Fieldwork at Broom was also funded through the British Academy (SG-31110) and the University of Southampton (Department of Archaeology). Our thanks to The Dorset Natural History and Archaeological Society at The Dorset County Museum for their permission to reproduce images and other material from the C.E. Bean archive (DORCM 1986.40.1-4), and for re-housing the C.E. Bean artefact collection from Broom in 2005 (DORCM 2005.35. AB820). Our thanks also to the staff of the Royal Albert Memorial Museum \& Art Gallery, Exeter, and particularly to John Allen, for kindly allowing us access to the museum's artefact collections from Broom. RH would like to thank Dr John McNabb and Dr Matthew Pope for their helpful comments on an earlier version of this paper, Dr Gilbert Marshall and Nick Ashton for discussions of the Broom bifaces, Dr Chris Green for discussions of the Bean archive and the Broom sediments, Dr Chris Norman for a valuable discussion on the Vale of Taunton material, Dr Stephen Dunn for kindly providing a copy of the FlipTest software, and Margaret Matthews for the artefact illustrations. Finally we'd both like to thank the three anonymous PPS referees for their valuable comments. Any remaining errors are of course our own. 


\section{REFERENCES}

Antoine, P., Coutard, J-P., Gibbard, P., Hallegouet, B., Lautridou, J-P. \& Ozouf, J-C. 2003. The Pleistocene rivers of the English Channel region. Journal of Quaternary Science 18(3-4), 227-243.

Ashton, N.M. 2001. One step beyond. Flint shortage above the Goring Gap: the example of Wolvercote. In S. Milliken and J. Cook (eds), A Very Remote Period Indeed: Papers on the Palaeolithic Presented to Derek Roe, 99-106. Oxford: Oxbow.

Ashton, N. 2008. Transport, curation and resharpening of lithics in the Lower Palaeolithic. Lithics: The Journal of the Lithic Studies Society 29, 6-17.

Ashton, N.M. \& Lewis, S.G. 2002. Deserted Britain: declining populations in the British Late Middle Pleistocene. Antiquity 76, 388-396.

Ashton, N.M. \& McNabb, J. 1994. Bifaces in Perspective. In N.M. Ashton and A. David (eds), Stories in Stone, 182-191. London: Lithic Studies Society (Occasional Paper No. 4).

Ashton, N.M. \& White, M.J. 2003. Bifaces and Raw Materials: Flexible Flaking in the British Early Palaeolithic. In M. Soressi and H.L. Dibble (eds), Multiple Approaches to the Study of Bifacial Technologies, 109-123. Philadelphia: University of Pennsylvania Museum Press.

Bordes, F. 1961. Typologie du Paléolithique ancien et moyen. Mémoires de l'Institut Préhistoriques de l'Université de Bordeaux 1. Bordeaux: Delmas.

Briant, R.M., Bates, M.R., Schwenninger, J-L. \& Wenban-Smith, F. 2006. An optically stimulated luminescence dated Middle to Late Pleistocene fluvial sequence from the western Solent Basin, southern England. Journal of Quaternary Science 21(5), 507-523.

Briant, R.M., Wenban-Smith, F.F. \& Schwenninger, J-L. 2009. Solent River gravels at Barton on Sea, Hampshire SZ 230 930. In R. Briant, M. Bates, R. Hosfield and F.F. Wenban-Smith (eds), The Quaternary of the Solent Basin and West Sussex Raised Beaches, 161-170. London: Quaternary Research Association.

Bridgland, D.R. 1994. The Quaternary of the Thames. London: Chapman \& Hall.

Bridgland, D.R. 2000. River terrace systems in north-west Europe: an archive of environmental change, uplift and early human occupation. Quaternary Science Reviews 19, 1293-1303. 
Bridgland, D.R. 2001. The Pleistocene Evolution and Palaeolithic Occupation of the Solent River. In F.F. Wenban-Smith and R.T. Hosfield (eds), Palaeolithic Archaeology of the Solent River, 15-25. London: Lithic Studies Society (Occasional Paper No. 7).

Calkin, J.B. \& Green, J.F.N. 1949. Palaeoliths and terraces near Bournemouth. Proceedings of the Prehistoric Society 15, 21-37.

Campbell, S., Hunt, C.O., Scourse, J.D., Keen, D.H. \& Stephens, N. 1998. Quaternary of South-West England. London: Chapman \& Hall.

Chambers, J.C. 2005a. Like a Rolling Stone? The Identification of Fluvial Transportation Damage Signatures on Secondary Context Bifaces. Lithics: The Newsletter of the Lithic Studies Society 24, 66-77.

Chambers, J.C. 2005b. River gravels and handaxes: new experiments in site formation, stone tool transportation and transformation. In M. Fansa (ed), Experimentelle Archäologie in Europa, Bilanz 2004, Heft 3, 25-41. Oldenburg: Isensee Verlag.

Clark, J.D. 2001. Variability in primary and secondary technologies of the Later Acheulian in Africa. In S. Milliken and J. Cook (eds), A Very Remote Period Indeed: Papers on the Palaeolithic Presented to Derek Roe, 1-18. Oxford: Oxbow.

Debénath, A. \& Dibble, H.L. 1994. Handbook of Palaeolithic Typology. Volume One: Lower and Middle Palaeolithic of Europe. Philadelphia: University of Pennsylvania.

Edwards, R.A. \& Gallois, R. 2004. Geology of the Sidmouth district - a brief explanation of the geological map. Sheet Explanation of the British Geological Survey. 1:50 000 Sheets 326 and 340 Sidmouth (England and Wales). Nottingham: British Geological Survey.

Evans, J. 1872. The Ancient Stone Implements, Weapons and Ornaments of Great Britain $\left(1^{\text {st }}\right.$ edition). London: Longman.

Evans, J. 1897. The Ancient Stone Implements, Weapons and Ornaments of Great Britain ( $2^{\text {nd }}$ edition). London: Longmans, Green \& Co.

Goodwin, J.H. 1929. Part III. The Victoria West Industry. In A.J.H. Goodwin and C. Van Riet Lowe (eds), The Stone Age Cultures of South Africa: 53-71. Annals of the South African Museum 27, 1-289.

Green, C.P. 1974. Pleistocene gravels of the River Axe in south-western England, and their bearing on the southern limit of glaciation in Britain. Geological Magazine 111, 213-220. 
Green, C.P. 1988. The Palaeolithic site at Broom, Dorset, 1932-41: from the record of C.E. Bean, Esq., F.S.A. Proceedings of the Geologists' Association 99, 173-180.

Green, C.P. \& Hosfield, R.T. Forthcoming. New Investigations at Broom. In R.T. Hosfield and C.P. Green (eds), The Lower Palaeolithic Site at Broom. Oxford: Oxbow Books.

Green, J.F.N. 1947. Some gravels and gravel pits in Hampshire and Dorset. Proceedings of the Geologists Association 58, 128-143.

Hardaker, T. \& Dunn, S. 2005. The Flip Test - a new statistical measure for quantifying symmetry in stone tools. http://antiquity.ac.uk/ProjGall/hardaker/

Hopkinson, T. \& White, M.J. 2005. The Acheulean and the handaxe: structure and agency in the Palaeolithic. In C.S. Gamble and M. Porr (eds), The Hominid Individual in Context: Archaeological investigations of Lower \& Middle Palaeolithic landscapes, locales and artefacts, 13-28. London: Routledge (Taylor \& Francis).

Horton, A., Worssam, B.C., Whittow, J.B., Holyoak, D.T. \& Worsley, P. 1981. The Wallingford Fan Gravel. Philosophical Transactions of the Royal Society of London. Series B, Biological Sciences 293(1064), 215-255.

Hosfield, R.T. 2005. Individuals among palimpsest data: fluvial landscapes in Southern England. In C.S. Gamble and M. Porr (eds), The Hominid Individual in Context: Archaeological investigations of Lower and Middle Palaeolithic landscapes, locales and artefacts, 220-243. Abingdon: Routledge (Taylor \& Francis).

Hosfield, R.T. 2009. Modes of transmission and material culture patterns in craft skills. In S. Shennan (ed.), Pattern and Process in Cultural Evolution, 45-60. Berkeley: University of California Press.

Hosfield, R.T. \& Chambers, J.C. 2004. The Archaeological Potential of Secondary Contexts. London: English Heritage Archive Report (Project No. 3361).

Hosfield, R.T. \& Green, C.P. Forthcoming. History of Research: The Bean Archive. In R.T. Hosfield and C.P. Green (eds), The Lower Palaeolithic Site at Broom. Oxford: Oxbow Books. Hosfield, R.T., Brown, A.G., Basell, L.S. \& Hounsell, S. 2006. Beyond the caves: The Palaeolithic Rivers of South-West Britain. Geoscience in South-West England 11(3), 183190. 
Hosfield R.T., Brown, A.G., Basell, L., Hounsell, S. \& Young, R. 2007. The Palaeolithic Rivers of South-West Britain. London: English Heritage Archive Report (Project No. 3847).

Hosfield, R.T., Marshall, G.D. \& Chambers, J.C. Forthcoming. The Broom Lithic Assemblage. In R.T. Hosfield and C.P. Green (eds), The Lower Palaeolithic Site at Broom. Oxford: Oxbow Books.

Keeley, L. 1993. Microwear Analysis of Lithics. In R. Singer, B.G. Gladfelter and J.J. Wymer (eds), The Lower Palaeolithic Site at Hoxne, England, 129-138. Chicago: University of Chicago Press.

Kohn, M. \& Mithen, S. 1999. Handaxes: products of sexual selection? Antiquity 73, 518-526. Lacaille, A.D. 1954. Palaeoliths from the Lower Reaches of the Bristol Avon. The Antiquaries Journal XXXIV(1-2), 1-27.

Lericolais, G., Auffret, J-P. \& Bourillet, J-F. 2003. The Quaternary Channel River: seismic stratigraphy of its palaeo-valleys and deeps. Journal of Quaternary Science 18(3-4), 245260.

Machin, A.J. 2008. Why handaxes just aren't that sexy: a response to Kohn \& Mithen (1999). Antiquity 82(317), 761-765.

Machin, A.J. 2009. The role of the individual agent in Acheulean biface variability: a multifactorial model. Journal of Social Archaeology 9(1), 35-58.

Machin, A.J., Hosfield, R.T. \& Mithen. 2005. Testing the functional utility of handaxe symmetry: Fallow deer butchery with replica handaxes. Lithics: The Journal of the Lithic Studies Society 26, 23-37.

Machin, A.J., Hosfield, R.T. \& Mithen, S.J. 2007. Why are some handaxes symmetrical? Testing the influence of handaxe morphology on butchery effectiveness. Journal of Archaeological Science 34(6), 883-893.

Marshall, G.D. 2001. The Broom pits: a review of research and a pilot study of two Acheulian biface assemblages. In F.F. Wenban-Smith and R.T. Hosfield (eds), Palaeolithic Archaeology of the Solent River, 77-84. London: Lithic Studies Society (Occasional Paper No. 7).

Marshall, G.D., Gamble, C.S., Roe, D.A. \& Dupplaw, D. 2002. Lower Palaeolithic technology, raw material and population ecology. http://ads.ahds.ac.uk/catalogue/specColl/bifaces/ index.cfm 
Maw, G. 1864. On a supposed deposit of boulder-clay in North Devon. Quarterly Journal of the Geological Society of London 20, 445-451.

McNabb, J. 2001. The shape of things to come. A speculative essay on the role of the Victoria West phenomenon at Canteen Koppie, during the South African Earlier Stone Age. In S. Milliken and J. Cook (eds), A Very Remote Period Indeed: Papers on the Palaeolithic Presented to Derek Roe, 37-46. Oxford: Oxbow.

McNabb, J. 2007. The British Lower Palaeolithic: Stones in Contention. Abingdon: Routledge. McNabb, J., Binyon, F. \& Hazelwood, L. 2004. The Large Cutting Tools from the South African Acheulean and the Question of Social Traditions. Current Anthropology 45(5), 653677.

McNabb, J. \& Rivett, C. 2007. Getting round to the point: biface tip shape in the British Lower Palaeolithic. Lithics: The Journal of the Lithic Studies Society 28, 20-32.

McPherron, S. 1995. A re-examination of the British biface data. Lithics: The Newsletter of the Lithic Studies Society 16, 47-63.

McPherron, S. 2006. What typology can tell us about Acheulian handaxe production. In N. Goren-Inbar and G. Sharon (eds), Axe Age: Acheulian Toolmaking from Quarry to Discard, 267-285. London: Equinox Publishing Ltd.

Mithen, S. 1993. Individuals, Groups and the Palaeolithic Record: A Reply to Clark. Proceedings of the Prehistoric Society 59, 393-398.

Mithen, S.J. 1994. Technology and Society during the Middle Pleistocene: Hominid Group Size, Social Learning and Industrial Variability. Cambridge Archaeological Journal 4(1), 3-32. Mithen, S.J. 1996. Social learning and cultural tradition. In J. Steele and S. Shennan (eds), The Archaeology of Human Ancestry, 207-229. London: Routledge.

Mithen S.J. 1999. Imitation and cultural change: a view from the Stone Age, with specific reference to the manufacture of handaxes. In H.O. Box and K.R. Gibson (eds), Mammalian Social learning: Comparative and Ecological Approaches, 389-399. Cambridge: Cambridge University Press.

Mithen, S.J. 2008. 'Whatever turns you on': a response to Anna Machin, 'Why handaxes just aren't that sexy'. Antiquity 82(317), 766-769. 
Moir, J.R. 1936. Ancient Man in Devon. Proceedings of the Devon Archaeological Exploration Society 2, 264-275.

Newberry, J. 2002. Inland Flint in Prehistoric Devon: Sources, Tool-making Quality and Use. Proceedings of the Devon Archaeological Society 60, 1-36.

Norman, C. 2000. Early humans in the Vale of Taunton - a new perspective. In C. Webster (ed.), Somerset Archaeology, 53-58. Taunton: Somerset County Council.

Nowell, A. \& Chang, M.L. 2009. The Case Against Sexual Selection as an Explanation of Handaxe Morphology. PaleoAnthropology 2009, 77-88.

Petraglia, M.D., Shipton, C. \& Paddaya, K. 2005. Life and mind in the Acheulean. In C.S. Gamble and M. Porr (eds), The Hominid Individual in Context: Archaeological investigations of Lower and Middle Palaeolithic landscapes, locales and artefacts, 197-219. Abingdon: Routledge (Taylor \& Francis).

Pope, M., Russel, K. \& Watson, K. 2006. Biface form and structured behaviour in the Acheulean. Lithics: The Journal of the Lithic Studies Society 27, 44-57.

Roberts, M.B. \& Parfitt, S.A. 1999. Boxgrove. A Middle Pleistocene Hominid Site at Eartham Quarry, Boxgrove, West Sussex. London: English Heritage.

Roe, D.A. 1968. British Lower and Middle Palaeolithic handaxe groups. Proceedings of the Prehistoric Society 34, 1-82.

Roe, D.A. 1971. Palaeolithic Artefacts from the River Avon terraces near Bristol. Proceedings of the University of Bristol Speleological Society 13(3), 319-326.

Roe, D.A. 1981. The Lower and Middle Palaeolithic periods in Britain. London: Routledge \& Kegan Paul.

Roe, D.A. 2001. Some Earlier Palaeolithic Find-Spots of Interest in the Solent Region. In F.F. Wenban-Smith and R.T. Hosfield (eds), Palaeolithic Archaeology of the Solent River, 47-56. London: Lithic Studies Society (Occasional Paper No. 7).

Roux, V. \& Bril, B. (eds). 2005. Stone Knapping: the necessary conditions for a uniquely hominin behaviour. Cambridge: McDonald Institute of Archaeological Research.

Salter, A.E. 1898. Pebbly and other gravels in Southern England. Proceedings of the Geologists' Association XV: 264-286. 
Sampson, C.G. (ed). 1978. Palaeoecology and Archaeology of an Acheulean Site at Caddington, England. Dallas: Department of Anthropology, Institute for the Study of Earth and Man, Southern Methodist University.

Schreve, D.C. 2001. Differentiation of the British late Middle Pleistocene interglacials: the evidence from mammalian biostratigraphy. Quaternary Science Reviews 20, 1693-1705.

Shakesby, R.A. \& Stephens, N. 1984. The Pleistocene gravels of Axe Valley, Devon. Report of the Transactions of the Devon Association for the Advancement of Science 116, 77-88.

Sharon, G. 2007. Acheulian Large Flake Industries: Technology, Chronology, and Significance. Oxford: Archaeopress (BAR International Series No. S1701).

Sharon, G. 2008. The impact of raw material on Acheulian large flake production. Journal of Archaeological Science 35(5), 1329-1344.

Sharon, G. \& Beaumont, P. 2006. Victoria West: a highly standardized prepared core technology. In N. Goren-Inbar and G. Sharon (eds), Axe Age: Acheulian toolmaking from Quarry to Discard, 181-199. London: Equinox Publishing Ltd.

Shaw, A.D. \& White, M.J. 2003. Another Look at the Cuxton Handaxe Assemblage. Proceedings of the Prehistoric Society 69, 305-313.

Stephens, N. 1974. The Chard Area and Axe Valley Sections. In A. Straw (ed.), Field Handbook for the Quaternary Research Association: Easter Meeting 1974, 46-51. Exeter: Quaternary Research Association.

Toms, P., Hosfield, R.T., Chambers, J.C., Green, C.P. \& Marshall, P. 2005. Optical dating of the Broom Palaeolithic sites, Devon \& Dorset. London: English Heritage (Centre for Archaeology Report No. 16/2005).

Tyldesley, J.A. 1987. The bout coupé handaxe: a typological problem. Oxford: British Archaeological Reports (British Series No. 170).

Villa, P. 2001. Early Italy and the colonization of Western Europe. Quaternary International $75,113-130$.

Wenban-Smith, F.F. 2004. Handaxe typology and Lower Palaeolithic cultural development: ficrons, cleavers and two giant handaxes from Cuxton. Lithics: The Journal of the Lithic Studies Society 25, 11-21. 
Wenban-Smith, F.F. \& Hosfield, R.T. (eds). 2001. Palaeolithic Archaeology of the Solent River. London: Lithic Studies Society (Occasional Paper No. 7).

Wenban-Smith, F.F., Gamble, C.S. \& ApSimon, A. 2000. The Lower Palaeolithic Site at Red Barns, Porchester: Bifacial technology, Raw Material Quality, and the Organisation of Archaic Behaviour. Proceedings of the Prehistoric Society 66, 209-256.

Wessex Archaeology. 1993. The Southern Rivers Palaeolithic Project. Report No. 2. 1992 1993. The South West and South of the Thames. Salisbury: Wessex Archaeology \& English Heritage.

Westaway, R., Bridgland, D.R. \& White, M.J. 2006. The Quaternary uplift history of central southern England: evidence from the terraces of the Solent River system and nearby raised beaches. Quaternary Science Reviews 25, 2212-2250.

White, M.J. 1998a. On the significance of Acheulean biface variability in southern Britain. Proceedings of the Prehistoric Society 64, 15-44.

White, M.J. 1998b. Twisted Ovate Bifaces in the British Lower Palaeolithic: Some Observations and Implications. In N.M. Ashton, F. Healy and P. Pettitt (eds), Stone Age Archaeology: Essays in Honour of John Wymer, 98-104. London: Oxbow Books (Oxbow Monograph No. 102 \& Lithic Studies Society Occasional Paper No. 6).

White, M.J. 2006. Axeing cleavers: reflections on broad-tipped large cutting tools in the British earlier Palaeolithic. In N. Goren-Inbar and G. Sharon (eds), Axe Age: Acheulian Toolmaking from Quarry to Discard, 365-386. London: Equinox Publishing Ltd.

White, M.J. \& Jacobi, R. 2002. Two sides to every story: bout coupé handaxes revisited. Oxford Journal of Archaeology 21, 109-133.

White, M.J. \& Plunkett, S. 2004. Miss Layard Excavates: a Palaeolithic site at Foxhall Road, Ipswich, 1903-1905. Liverpool: Western Academic \& Specialist Press Limited.

White, M.J. \& Schreve, D.S. 2000. Island Britain - Peninsula Britain: Palaeogeography, Colonisation and the Lower Palaeolithic Settlement of the British Isles. Proceedings of the Prehistoric Society 66, 1-28.

White, M., Scott, R. \& Ashton, N. 2006. The Early Middle Palaeolithic in Britain: archaeology, settlement history and human behaviour. Journal of Quaternary Science 21(5), 525-541. 
Whittaker, K., Beasley, M., Bates, M.R. \& Wenban-Smith, F.F. 2004. The Lost Valley. British Archaeology 74, 22-27.

Winton, V. 2004. A study of Palaeolithic artefacts from selected sites on deposits mapped as clay-with-flints of Southern England: with particular reference to handaxe manufacture. Oxford: Archaeopress (BAR British Series No. 360).

Woodward, H.B. \& Ussher, W.A.E. 1911. The Geology of the country near Sidmouth and Lyme Regis. Memoirs of the Geological Survey. England and Wales. Explanation of Sheets 326 \& 340. London: HMSO.

Wymer, J.J. 1968. Lower Palaeolithic Archaeology in Britain, as Represented by the Thames Valley. London: John Baker.

Wymer, J.J. 1999. The Lower Palaeolithic Occupation of Britain (Vol. 1 \& 2). Salisbury: Wessex Archaeology \& English Heritage. 
Hosfield \& Chambers

Genuine Diversity? The Broom biface assemblage

Table 1: Asymmetrical biface proportions from selected British Lower Palaeolithic sites (after Marshall et al. 2002). ${ }^{1}$ Asymmetrical pieces identified according to either: Bean's 'lop-sided' type 4 planform (Figure 3); an irregular planform and/or 'non-classic' in type (after Ashton \& McNabb 1994; e.g. Acheulean Biface Database records 435 \& 436 (Cuxton): Marshall et al. 2002); or asymmetry created by tranchet intersection flaking at the tip (e.g. Acheulean Biface Database record 3210 (Boxgrove): Marshall et al. 2002). ${ }^{2}$ Asymmetrical pieces identified according to Bean's 'lop-sided' type 4 planform (Figure 3). MIS dates after McNabb (2007).

\begin{tabular}{|c|c|c|c|c|c|}
\hline Site & Age (MIS) & $\begin{array}{l}\text { No. of } \\
\text { bifaces }\end{array}$ & $\begin{array}{r}\text { No. of asymmetrical } \\
\text { bifaces }^{1}\end{array}$ & $\%$ & $\begin{array}{l}\text { No. of asymmetrical } \\
\text { ses ('lop-sided' only) }\end{array}$ \\
\hline Boxgrove & 13 & 183 & 25 & 13.7 & 23 \\
\hline Corfe Mullen & $13 /$ early $12 ?$ & 138 & 42 & 30.4 & 22 \\
\hline Bowman's Lodge & 11 & 29 & 8 & 27.6 & 7 \\
\hline Cuxton & $9 ?$ & 214 & 136 & 63.6 & 47 \\
\hline
\end{tabular}


Hosfield \& Chambers

Genuine Diversity? The Broom biface assemblage

Table 2: 12 OSL samples from the Broom fluvial deposits (after Toms et al. 2005: Tables 1 \& 2)

\begin{tabular}{|c|c|c|c|c|c|c|c|}
\hline Laboratory & Sedimentary & Section & Total Dose Rate & Mean $D_{e}(G y)$ & Mean age & MIS & Bayesian model age \\
\hline Code & Unit & & $\left(G y \cdot k a^{-1}\right)$ & & (kya) & & estimate ( $1 \sigma$ confidence) \\
\hline GL02082 & Upper Gravels & 1 & $1.72 \pm 0.11$ & $503.4 \pm 27.8$ & $293 \pm 24$ & $9-8$ & \\
\hline GL02085 & Upper Gravels & 9 & $1.27 \pm 0.08$ & $353.4 \pm 21.4$ & $279 \pm 24$ & $9-8$ & \\
\hline GL03006 & Upper Gravels & 9 & $1.36 \pm 0.08$ & $375.9 \pm 27.1$ & $277 \pm 25$ & $9-8$ & \\
\hline GL03007 & Upper Gravels & 9 & $1.19 \pm 0.06$ & $324.0 \pm 20.8$ & $271 \pm 22$ & 8 & 292-205 kya \\
\hline GL03009 & Upper Gravels & 13 & $1.27 \pm 0.06$ & $343.0 \pm 18.6$ & $270 \pm 19$ & 8 & (Upper Gravels) \\
\hline GL03004 & Upper Gravels & 9 & $1.08 \pm 0.05$ & $288.3 \pm 19.1$ & $268 \pm 22$ & 8 & \\
\hline GL03008 & Upper Gravels & 13 & $1.45 \pm 0.07$ & $352.8 \pm 18.9$ & $244 \pm 18$ & $8-7$ & \\
\hline GL03005 & Upper Gravels & 9 & $1.45 \pm 0.07$ & $326.8 \pm 17.3$ & $226 \pm 16$ & 7 & \\
\hline GL03011 & Middle Beds & 2 & $1.84 \pm 0.10$ & $546.0 \pm 44.8$ & $297 \pm 29$ & $9-8$ & \\
\hline GL02083 & Middle Beds & 2 & $1.61 \pm 0.08$ & $461.5 \pm 28.0$ & $287 \pm 22$ & $9-8$ & 324-282 kya \\
\hline GL02084 & Middle Beds & 2 & $1.73 \pm 0.10$ & $483.0 \pm 21.0$ & $279 \pm 20$ & 8 & (Middle Beds) \\
\hline GL03010 & Middle Beds & 2 & $1.61 \pm 0.12$ & $380.6 \pm 28.0$ & $237 \pm 25$ & $8-7$ & \\
\hline
\end{tabular}


Hosfield \& Chambers

Genuine Diversity? The Broom biface assemblage

Table 3a: Biface typology, raw material, and planform (asymmetry and plano-convex profile) attributes in the sampled Broom assemblage. ${ }^{1} \mathrm{CGC}$ : Coarsegrained chert; MGC: Medium-grained chert; FGC: Fine-grained chert; F: Flint; Q: Quartzite. ${ }^{2}$ Asymmety and plano-convex percentages calculated as \% of total no. of asymmetrical/plano-convex bifaces within the biface type sample (e.g. \% of 98 for asymmetry in cordate/ovate bifaces), and sub-divided by raw material types.

\begin{tabular}{|c|c|c|c|c|c|c|c|c|}
\hline \multirow{2}{*}{$\begin{array}{l}\text { Biface type (Wymer } \\
\text { 1968) }\end{array}$} & \multirow[t]{2}{*}{$\mathbf{n}$} & \multicolumn{3}{|c|}{ Raw material $^{1}$} & \multicolumn{2}{|c|}{ Asymmetrical $^{2}$} & \multicolumn{2}{|c|}{ Plano-convex ${ }^{2}$} \\
\hline & & Category & $\mathrm{n}$ & $\%$ & $\mathrm{n}$ & $\%$ & $\mathrm{n}$ & $\%$ \\
\hline \multirow[t]{4}{*}{ Cordate/Ovate $(\mathrm{J} / \mathrm{K})$} & 272 & CGC & 58 & 21.3 & 20 & 20.4 & 16 & 26.2 \\
\hline & & MGC & 134 & 49.3 & 49 & 50.0 & 28 & 45.9 \\
\hline & & FGC & 64 & 23.5 & 25 & 25.5 & 11 & 18.0 \\
\hline & & $\mathrm{F}$ & 16 & 5.9 & 4 & 4.1 & 6 & 9.8 \\
\hline Totals & & - & 272 & 100.0 & 98 & 100.0 & 61 & 100.0 \\
\hline \multirow[t]{4}{*}{ Cordate (J) } & 183 & CGC & 34 & 18.6 & 10 & 20.0 & 8 & 22.9 \\
\hline & & MGC & 89 & 48.6 & 28 & 56.0 & 15 & 42.3 \\
\hline & & FGC & 53 & 29.0 & 11 & 22.0 & 12 & 34.2 \\
\hline & & $\mathrm{F}$ & 7 & 3.8 & 1 & 2.0 & 0 & 0.0 \\
\hline
\end{tabular}




\begin{tabular}{|c|c|c|c|c|c|c|c|c|}
\hline Totals & & - & 183 & 100.0 & 50 & 100.0 & 35 & 100.0 \\
\hline \multirow[t]{5}{*}{ Pointed (F) } & 109 & CGC & 16 & 14.7 & 3 & 25.0 & 3 & 12.0 \\
\hline & & MGC & 57 & 52.3 & 7 & 58.3 & 15 & 60.0 \\
\hline & & FGC & 28 & 25.7 & 2 & 16.7 & 7 & 28.0 \\
\hline & & $\mathrm{F}$ & 7 & 6.4 & 0 & 0.0 & 0 & 0.0 \\
\hline & & Q & 1 & 0.9 & 0 & 0.0 & 0 & 0.0 \\
\hline Totals & & - & 109 & 100.0 & 12 & 100.0 & 25 & 100.0 \\
\hline \multirow[t]{4}{*}{ Ovate (K) } & 65 & CGC & 9 & 13.8 & 2 & 12.5 & 0 & 0.0 \\
\hline & & MGC & 31 & 47.7 & 8 & 50.0 & 7 & 58.3 \\
\hline & & FGC & 23 & 35.4 & 5 & 31.3 & 5 & 41.7 \\
\hline & & $\mathrm{F}$ & 2 & 3.1 & 1 & 6.2 & 0 & 0.0 \\
\hline Totals & & - & 65 & 100.0 & 16 & 100.0 & 12 & 100.0 \\
\hline \multirow[t]{3}{*}{ Sub-cordate (G) } & 54 & CGC & 10 & 18.5 & 1 & 12.5 & 2 & 22.2 \\
\hline & & MGC & 26 & 48.1 & 3 & 37.5 & 4 & 44.5 \\
\hline & & FGC & 12 & 22.2 & 4 & 50.0 & 2 & 22.2 \\
\hline \multirow[t]{2}{*}{ Totals } & & $\mathrm{F}$ & 6 & 11.1 & 0 & 0.0 & 1 & 11.1 \\
\hline & & - & 54 & 100.0 & 8 & 100.0 & 9 & 100.0 \\
\hline
\end{tabular}


Hosfield \& Chambers

Genuine Diversity? The Broom biface assemblage

Table 3b: Biface tip, butt, and edge profile attributes in the sampled Broom assemblage. ${ }^{1}$ IR: Irregular rounded; R: Rounded; IP: Irregular point; LP: Lingulate point; OP: Ogee point. ${ }^{2}$ Tip, butt and edge profile percentages calculated as \% of total biface type sample (e.g. \% of 183 for cordate bifaces). ${ }^{3}$ TF: Trimmed flat; T: Trimmed; PT/PC: Part-trimmed/part-cortical; Nat: Natural. ${ }^{4}$ St/St: Straight/straight edge profiles; St/Sin: Straight/sinuous edge profiles; Sin/Sin: Sinuous/sinuous edge profiles; S-twist: S-twist edge profile.

\begin{tabular}{|c|c|c|c|c|c|c|c|c|c|c|}
\hline \multirow{2}{*}{$\begin{array}{l}\text { Biface type (Wymer } \\
\text { 1968) }\end{array}$} & \multirow[t]{2}{*}{$\mathbf{n}$} & \multicolumn{3}{|c|}{ Tip type $^{1}$} & \multicolumn{3}{|c|}{ Butt type ${ }^{3}$} & \multicolumn{3}{|c|}{ Edge profile $^{4}$} \\
\hline & & Category & $\mathrm{n}$ & $\%^{2}$ & Category & $\mathrm{n}$ & $\%^{2}$ & Category & $\mathrm{n}$ & $\%$ \\
\hline \multirow[t]{3}{*}{ Cordate/Ovate (J/K) } & 272 & IR & 153 & 56.3 & TF & 186 & 68.4 & $\mathrm{St} / \mathrm{St}$ & 140 & 51.5 \\
\hline & & $\mathrm{R}$ & 43 & 15.8 & $\mathrm{~T}$ & 53 & 19.5 & St/Sin & 69 & 25.4 \\
\hline & & OP & 22 & 8.1 & Nat & 11 & 4.0 & S-twist & 8 & 2.9 \\
\hline Totals & & - & 232 & 85.3 & - & 269 & 98.9 & - & 269 & 98.9 \\
\hline \multirow[t]{2}{*}{ Cordate (J) } & 183 & IR & 64 & 35.0 & TF & 142 & 77.6 & $\mathrm{St} / \mathrm{St}$ & 96 & 52.5 \\
\hline & & OP & 27 & 14.8 & Nat & 9 & 4.9 & S-twist & 11 & 6.0 \\
\hline
\end{tabular}




\begin{tabular}{|c|c|c|c|c|c|c|c|c|c|c|}
\hline Totals & & - & 139 & 76.0 & - & 183 & 100.0 & - & 183 & 100.0 \\
\hline \multirow[t]{4}{*}{ Pointed (F) } & 109 & IR & 24 & 22.0 & TF & 37 & 33.9 & $\mathrm{St} / \mathrm{St}$ & 50 & 45.9 \\
\hline & & $\mathrm{R}$ & 16 & 14.7 & $\mathrm{~T}$ & 32 & 29.4 & $\mathrm{St} / \mathrm{Sin}$ & 29 & 26.6 \\
\hline & & LP & 12 & 11.0 & Nat & 20 & 18.3 & $\operatorname{Sin} / \operatorname{Sin}$ & 26 & 23.9 \\
\hline & & OP & 18 & 16.5 & PT/PC & 14 & 12.8 & S-Twist & 4 & 3.7 \\
\hline Totals & & - & 70 & 64.2 & - & 103 & 94.4 & - & 109 & 100.0 \\
\hline \multirow[t]{4}{*}{ Ovate (K) } & 65 & IR & 38 & 58.5 & TF & 49 & 75.4 & $\mathrm{St} / \mathrm{St}$ & 24 & 36.9 \\
\hline & & $\mathrm{R}$ & 18 & 27.7 & $\mathrm{~T}$ & 10 & 15.4 & $\mathrm{St} / \mathrm{Sin}$ & 18 & 27.7 \\
\hline & & IP & 1 & 1.5 & PT/PC & 2 & 3.1 & $\operatorname{Sin} / \operatorname{Sin}$ & 16 & 24.6 \\
\hline & & OP & 1 & 1.5 & Nat & 1 & 1.5 & S-twist & 7 & 10.8 \\
\hline Totals & & - & 58 & 89.2 & - & 62 & 95.4 & - & 65 & 100.0 \\
\hline \multirow[t]{3}{*}{ Sub-cordate (G) } & 54 & IR & 33 & 61.1 & TF & 27 & 50.0 & $\mathrm{St} / \mathrm{St}$ & 19 & 35.2 \\
\hline & & $\mathrm{R}$ & 3 & 5.6 & $\mathrm{~T}$ & 20 & 37.0 & $\mathrm{St} / \mathrm{Sin}$ & 18 & 33.3 \\
\hline & & IP & 5 & 9.3 & $\mathrm{PT} / \mathrm{PC}$ & 5 & 9.3 & $\operatorname{Sin} / \operatorname{Sin}$ & 17 & 31.5 \\
\hline \multirow[t]{2}{*}{ Totals } & & OP & 5 & 9.3 & Nat & 2 & 3.7 & - & - & - \\
\hline & & - & 46 & 85.3 & - & 54 & 100.0 & - & 54 & 100.0 \\
\hline
\end{tabular}


Hosfield \& Chambers

Genuine Diversity? The Broom biface assemblage

Table 4: Index of symmetry measures for Broom biface assemblage sample (FlipTest software; @ Hardaker \& Dunn). 1.00-1.49: Virtually perfect; 1.50-2.99:

Very high; 3.00-3.99: High; 4.00-4.99: Moderate; 5.00-5.99: Low; 6.00+: Very low. Data generated using the FlipTest Auto Mode, Auto-Rotation settings.

$\begin{array}{lcccccccc}\text { Sample } & \mathbf{n} & \text { Mean } & \text { Mode } & \text { Median } & \text { S.D. } & \text { Min. } & \text { Max. } & \text { Range } \\ \text { 'Symmetrical' } & 30 & 3.94 & 3.45 & 1.56 & 1.56 & 1.67 & 7.35 & 5.68 \\ \text { Asymmetrical } & 30 & 5.94 & 6.09 & 5.84 & 1.82 & 2.70 & 9.88 & 7.18\end{array}$


Hosfield \& Chambers

Genuine Diversity? The Broom biface assemblage

Table 5: Selected biface metrics and technological aspects in the sampled Broom assemblage, by raw material type. Mean values (selected standard deviation values in brackets). ${ }^{1}$ Flake scar measures standardised for biface length (i.e. no. of flake scars/length). ${ }^{2}$ Th/B: Thickness/breadth $=$ refinement (definition of ovates after Roe 1968); ${ }^{3} \mathrm{~T}_{1} / \mathrm{L}$ : Tip thickness/length = tip refinement (definition of points after Roe 1968); ${ }^{4}$ Percentage values calculated according to the total number of positively identified blanks in each raw material category.

\begin{tabular}{|c|c|c|c|c|c|c|c|c|c|c|c|}
\hline Raw material & $\mathbf{n}$ & $\begin{array}{r}\text { Weight } \\
\text { (g) }\end{array}$ & $\begin{array}{r}\text { Length } \\
(\mathrm{mm})\end{array}$ & $\begin{array}{l}\text { Breadth } \\
(\mathrm{mm})\end{array}$ & $\begin{array}{r}\text { Thickness } \\
(\mathrm{mm})\end{array}$ & $\begin{array}{r}\text { Flake scars } \\
(<10 \mathrm{~mm})^{1}\end{array}$ & $\begin{array}{r}\text { Cortex } \\
\%\end{array}$ & $\begin{array}{r}\text { Th/B }{ }^{2} \text { (all } \\
\text { bifaces) }\end{array}$ & $\begin{array}{r}\mathrm{Th} / \mathrm{B}^{2} \\
\text { (ovates) }\end{array}$ & $\begin{array}{r}\mathrm{T}_{1} / \mathrm{L}^{3} \\
\text { (points) }\end{array}$ & $\begin{array}{r}\text { Flake blank } \\
\%^{4}\end{array}$ \\
\hline Flint & 55 & $\begin{array}{r}341.1 \\
(184.1)\end{array}$ & $\begin{array}{l}122.2 \\
(31.6)\end{array}$ & $\begin{array}{r}79.9 \\
(13.6)\end{array}$ & $\begin{array}{l}33.6 \\
(8.9)\end{array}$ & 0.315 & 8.2 & 0.421 & 0.402 & 0.150 & 34.8 \\
\hline $\begin{array}{l}\text { Fine-grained } \\
\text { chert }\end{array}$ & 269 & $\begin{array}{r}391.5 \\
(213.0)\end{array}$ & $\begin{array}{l}128.9 \\
(32.4)\end{array}$ & $\begin{array}{r}85.0 \\
(15.5)\end{array}$ & $\begin{array}{l}33.8 \\
(7.2)\end{array}$ & 0.263 & 9.7 & 0.397 & 0.392 & 0.151 & 56.4 \\
\hline $\begin{array}{l}\text { Medium- } \\
\text { grained chert }\end{array}$ & 474 & $\begin{array}{r}429.2 \\
(243.1)\end{array}$ & $\begin{array}{l}133.5 \\
(32.3)\end{array}$ & $\begin{array}{r}87.5 \\
(16.0)\end{array}$ & $\begin{array}{l}34.7 \\
(8.1)\end{array}$ & 0.252 & 7.0 & 0.397 & 0.393 & 0.149 & 58.9 \\
\hline $\begin{array}{l}\text { Coarse- } \\
\text { grained chert }\end{array}$ & 178 & $\begin{array}{r}473.4 \\
(209.2)\end{array}$ & $\begin{array}{l}141.1 \\
(30.1)\end{array}$ & $\begin{array}{r}91.5 \\
(14.6)\end{array}$ & $\begin{array}{l}36.3 \\
(6.7)\end{array}$ & 0.219 & 7.2 & 0.397 & 0.399 & 0.149 & 59.4 \\
\hline
\end{tabular}


Hosfield \& Chambers

Genuine Diversity? The Broom biface assemblage

Table 6: Selected biface metrics and technological aspects in the sampled Broom assemblage, by principal biface type (after Wymer 1968). Mean values.

${ }^{1}$ Flake scar measures standardised for biface length (i.e. no. of flake scars/length). ${ }^{2} \mathrm{~B} / \mathrm{L}$ : Breadth/length $=$ elongation; ${ }^{3} \mathrm{Th} / \mathrm{B}$ : Thickness/breadth $=$ refinement;

${ }^{4} \mathrm{~T}_{1} / \mathrm{T}_{2}$ : Tip thickness/butt thickness $=$ profile shape.

\begin{tabular}{|c|c|c|c|c|c|c|c|c|c|}
\hline $\begin{array}{l}\text { Biface type } \\
\text { (Wymer 1968) }\end{array}$ & $\mathbf{n}$ & $\begin{array}{r}\text { Length } \\
(\mathrm{mm})\end{array}$ & $\begin{array}{l}\text { Breadth } \\
\qquad(\mathrm{mm})\end{array}$ & $\begin{array}{r}\text { Thickness } \\
(\mathrm{mm})\end{array}$ & $\begin{array}{l}\text { Flake scars } \\
\qquad(<10 \mathrm{~mm})^{1}\end{array}$ & $\begin{array}{r}\text { Cortex } \\
\%\end{array}$ & $B / L^{2}$ & $\mathrm{Th} / \mathrm{B}^{3}$ & $T_{1} / T_{2}{ }^{4}$ \\
\hline Point (F) & 109 & 134.1 & 78.7 & 36.6 & 0.250 & 10.1 & 0.587 & 0.465 & 0.567 \\
\hline Sub-Cordate (G) & 54 & 126.6 & 92.9 & 34.3 & 0.233 & 3.8 & 0.734 & 0.369 & 0.688 \\
\hline Cordate (J) & 183 & 126.4 & 88.5 & 32.2 & 0.281 & 5.0 & 0.700 & 0.364 & 0.707 \\
\hline Ovate (K) & 65 & 114.9 & 80.7 & 30.7 & 0.289 & 5.0 & 0.702 & 0.380 & 0.755 \\
\hline
\end{tabular}


Hosfield \& Chambers

Genuine Diversity? The Broom biface assemblage

Table 7: Selected biface metrics and technological aspects in the sampled Broom assemblage, by blank type, presence/absence of asymmetry, and presence of tranchet flaking. Mean values (selected standard deviation values in parenthesis). ${ }^{1}$ Flake scar measures standardised for biface length (i.e. no. of flake scars/length). ${ }^{2} \mathrm{~B} / \mathrm{L}:$ Breadth/length = elongation; ${ }^{3} \mathrm{Th} / \mathrm{B}$ : Thickness/breadth $=$ refinement; ${ }^{4} \mathrm{~T}_{1} / \mathrm{T}_{2}:$ Tip thickness $/$ butt thickness $=$ profile shape.

\begin{tabular}{|c|c|c|c|c|c|c|c|c|c|c|}
\hline Biface category & $\mathbf{n}$ & $\begin{array}{r}\text { Weight } \\
(\mathrm{g})\end{array}$ & $\begin{array}{r}\text { Length } \\
(\mathrm{mm})\end{array}$ & $\begin{array}{l}\text { Breadth } \\
\qquad(\mathrm{mm})\end{array}$ & $\begin{array}{r}\text { Thickness } \\
(\mathrm{mm})\end{array}$ & $\begin{array}{l}\text { Flake scars } \\
\qquad(<10 \mathrm{~mm})^{1}\end{array}$ & $\begin{array}{r}\text { Cortex } \\
\%\end{array}$ & $B / L^{2}$ & $\mathrm{Th} / \mathrm{B}^{3}$ & $\mathbf{T}_{1} / \mathbf{T}_{2}{ }^{4}$ \\
\hline Flake blank & 220 & 388.3 & 130.7 & 86.3 & 32.7 & 0.227 & 6.4 & 0.660 & 0.379 & 0.641 \\
\hline Cobble blank & 149 & 443.4 & 134.4 & 85.8 & 38.3 & 0.216 & 20.7 & 0.638 & 0.446 & 0.585 \\
\hline Asymmetrical & 232 & $\begin{array}{r}474.9 \\
(210.9)\end{array}$ & $\begin{array}{l}141.7 \\
(30.0)\end{array}$ & $\begin{array}{r}91.9 \\
(13.5)\end{array}$ & $\begin{array}{l}34.8 \\
(5.9)\end{array}$ & 0.243 & 6.0 & 0.649 & 0.379 & 0.649 \\
\hline 'Symmetrical' & 745 & $\begin{array}{r}405.6 \\
(230.9)\end{array}$ & $\begin{array}{l}130.3 \\
(32.4)\end{array}$ & $\begin{array}{r}85.7 \\
(16.0)\end{array}$ & $\begin{array}{l}34.7 \\
(8.2)\end{array}$ & 0.256 & 8.4 & 0.658 & 0.405 & 0.656 \\
\hline Tranchet-flaked & 53 & 471.6 & 139.6 & 90.3 & 36.5 & 0.256 & 5.7 & 0.647 & 0.404 & 0.647 \\
\hline
\end{tabular}


Hosfield \& Chambers

Genuine Diversity? The Broom biface assemblage

Table 8: Selected biface attributes through the Broom sequence (Middle Beds and Upper Gravels). ${ }^{1}$ F: Pointed biface; F/M: Pointed/Ficron biface; F/G:

Pointed/Sub-Cordate biface; G: Sub-Cordate biface; G/K: Sub-Cordate/Ovate biface; J: Cordate biface; J/K: Cordate/Ovate biface; K: Ovate biface. ${ }^{2} \mathrm{CGC}$ :

Coarse-grained chert; MGC: Medium-grained chert; FGC: Fine-grained chert; F: Flint. ${ }^{3}$ Flk: Flake blank; Cob: Cobble blank; Oth: Other identified blank forms;

ND: No data; Blank form percentages calculated as \% of total number of positively identified blank forms. ${ }^{4}$ IR: Irregular rounded; R: Rounded; AP: Acute point; BP: Basil point; IP: Irregular point; LP: Lingulate point; OP: Ogee point. ${ }^{5}$ TF: Trimmed flat; T: Trimmed; PT/PC: Part-trimmed/part-cortical; Nat: Natural. ${ }^{6} \mathrm{St} / \mathrm{St}$ : Straight/straight edge profiles; St/Sin: Straight/sinuous edge profiles; Sin/Sin: Sinuous/sinuous edge profiles. ${ }^{7}$ All percentages calculated as $\%$ of total biface sample (excluding the blank form data: see note ${ }^{3}$ above). The largest percentage category for each attribute is highlighted in bold italics for comparison.

\begin{tabular}{|c|c|c|c|c|c|c|c|c|c|c|c|c|c|c|c|c|c|c|c|}
\hline \multirow[t]{2}{*}{ Sample } & \multirow[t]{2}{*}{$\mathbf{n}$} & \multicolumn{3}{|c|}{$\begin{array}{c}\text { Biface type } \\
(\text { Wymer 1968) }\end{array}$} & \multicolumn{3}{|c|}{$\begin{array}{c}\text { Raw } \\
\text { material }^{2}\end{array}$} & \multicolumn{3}{|c|}{$\begin{array}{l}\text { Blank } \\
\text { form }^{3}\end{array}$} & \multicolumn{3}{|c|}{$\begin{array}{c}\text { Tip } \\
\text { type }^{4}\end{array}$} & \multicolumn{3}{|c|}{$\begin{array}{l}\text { Butt } \\
\text { type }^{5}\end{array}$} & \multicolumn{3}{|c|}{$\begin{array}{c}\text { Edge } \\
\text { profile }^{6}\end{array}$} \\
\hline & & & $n$ & $\%^{7}$ & & $n$ & $\%^{7}$ & & $\mathbf{N}$ & $\%$ & & $\mathrm{n}$ & $\%^{7}$ & & $n$ & $\%^{7}$ & & $n$ & $\%^{7}$ \\
\hline Upper & 22 & $\mathrm{~F}$ & 2 & 9.1 & CGC & 5 & 22.7 & Flk & 3 & 42.9 & IR & 7 & 31.8 & $T F$ & 10 & 45.5 & $\mathrm{St} / \mathrm{St}$ & 8 & 36.4 \\
\hline \multirow[t]{3}{*}{ Gravel } & & $F / G$ & 2 & 9.1 & $M G C$ & 10 & 45.3 & Cob & 4 & 57.1 & $\mathrm{R}$ & 3 & 13.6 & $\mathrm{~T}$ & 7 & 31.8 & St/Sin & 9 & 40.9 \\
\hline & & $G$ & 2 & 9.1 & FGC & 6 & 27.3 & Oth & 0 & 0.0 & LP & 2 & 9.1 & PT/PC & 4 & 18.2 & $\operatorname{Sin} / \operatorname{Sin}$ & 4 & 18.2 \\
\hline & & $\mathrm{G} / \mathrm{K}$ & 2 & 9.1 & $\mathrm{~F}$ & 1 & 4.5 & ND & 15 & & OP & 3 & 13.6 & Nat & 1 & 4.5 & & & \\
\hline
\end{tabular}




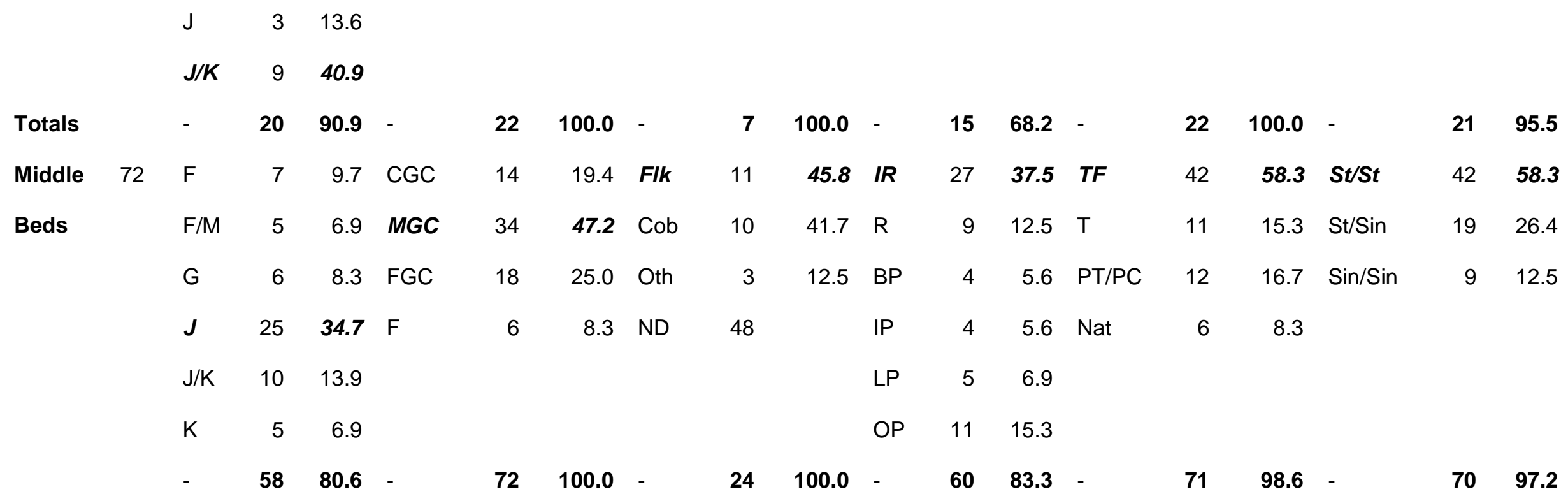




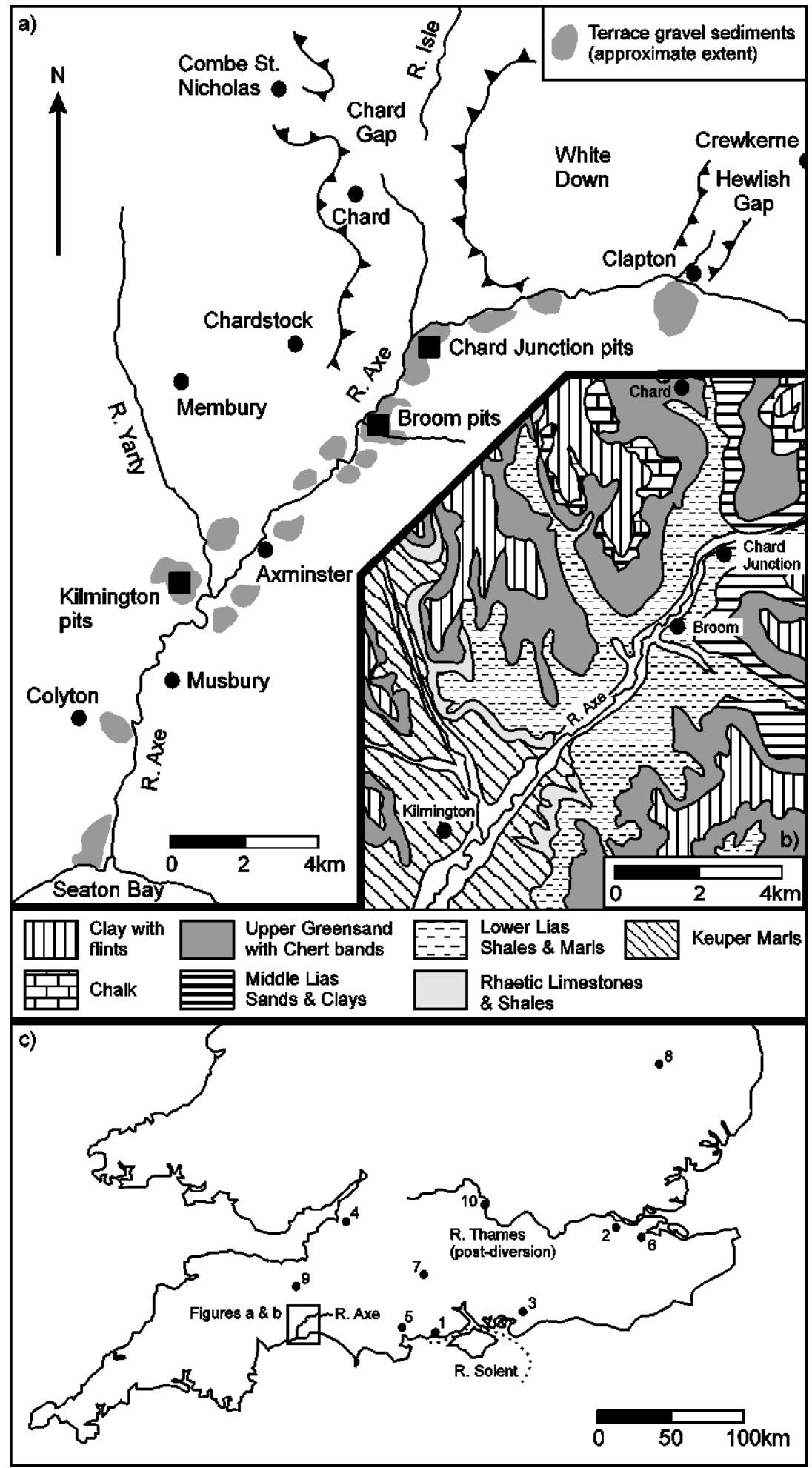

Figure 1: Location (a) and regional geology (b) of the River Axe, Britain (after Shakesby \&

Stephens 1984: Fig. 1) and selected British Lower Palaeolithic sites discussed in the text (c). $1 \mathrm{a}$ and $1 \mathrm{~b}$ reproduced with the permission of the Devonshire Association. 1: Barton Cliff; 2: Bowman's Lodge; 3: Boxgrove; 4: Bristol Avon; 5: Corfe Mullen; 6: Cuxton; 7: Harnham; 8: Santon Downham; 9: Vale of Taunton; 10: Wallingford. 


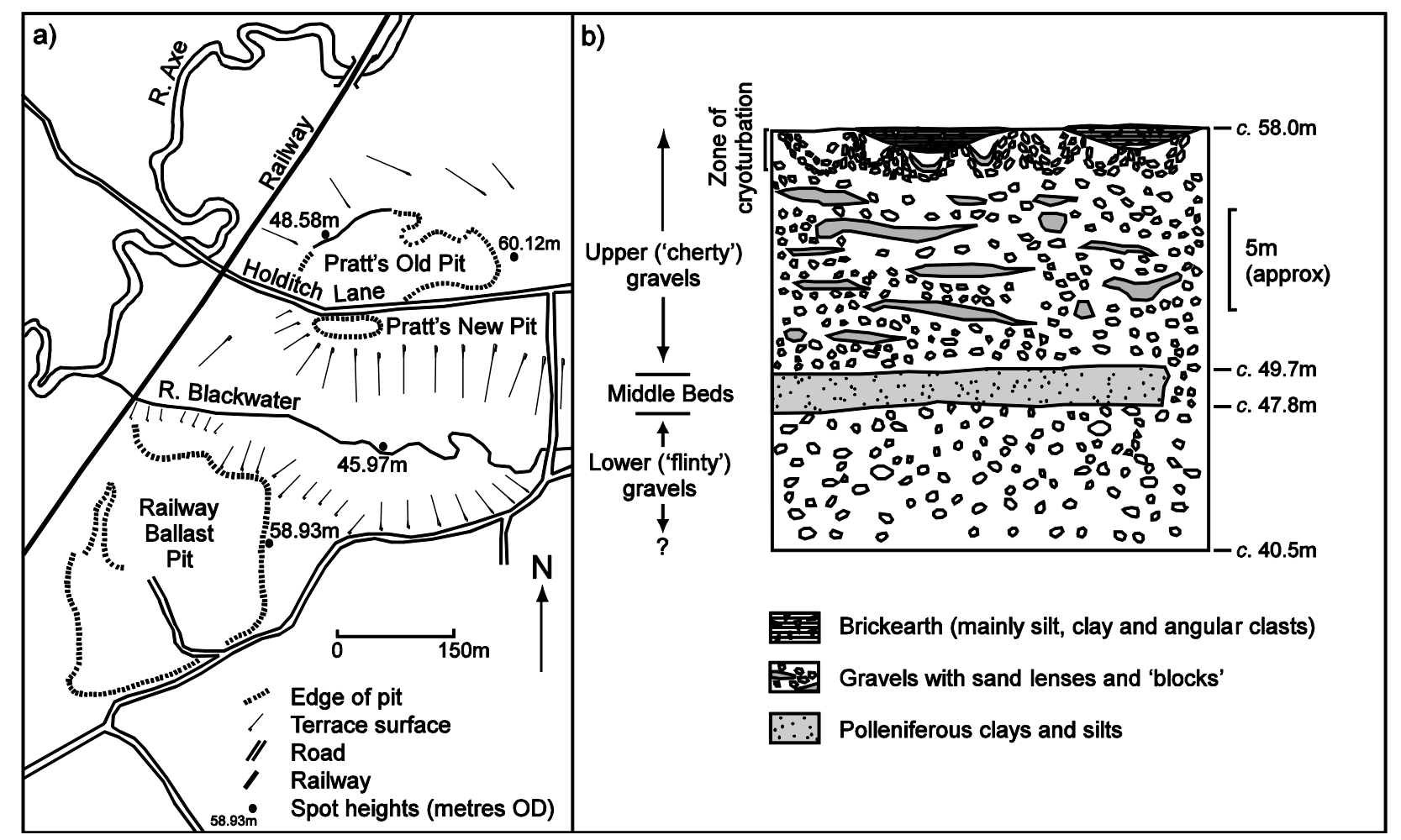

Figure 2: Gravel pit extents (a) and the geology of the Middle Pleistocene deposits (b) at Broom, Britain (after Campbell et al. 1998: Fig. 9.12, with kind permission of Springer Science and Business Media; Shakesby \& Stephens 1984: Fig. 2, reproduced with the permission of the Devonshire Association). The section (b) is generalised, based on observations in all three of the Broom pits. The approximate heights are based on C.E. Bean's observations of the 'typical' stratigraphy in Pratt's Old Pit (i.e. excluding the conformable dipping of the sediments in the south-east corner of the pit: the '1938 Locality') and Dr Nick Stephens' survey in the Railway Ballast Pit. 


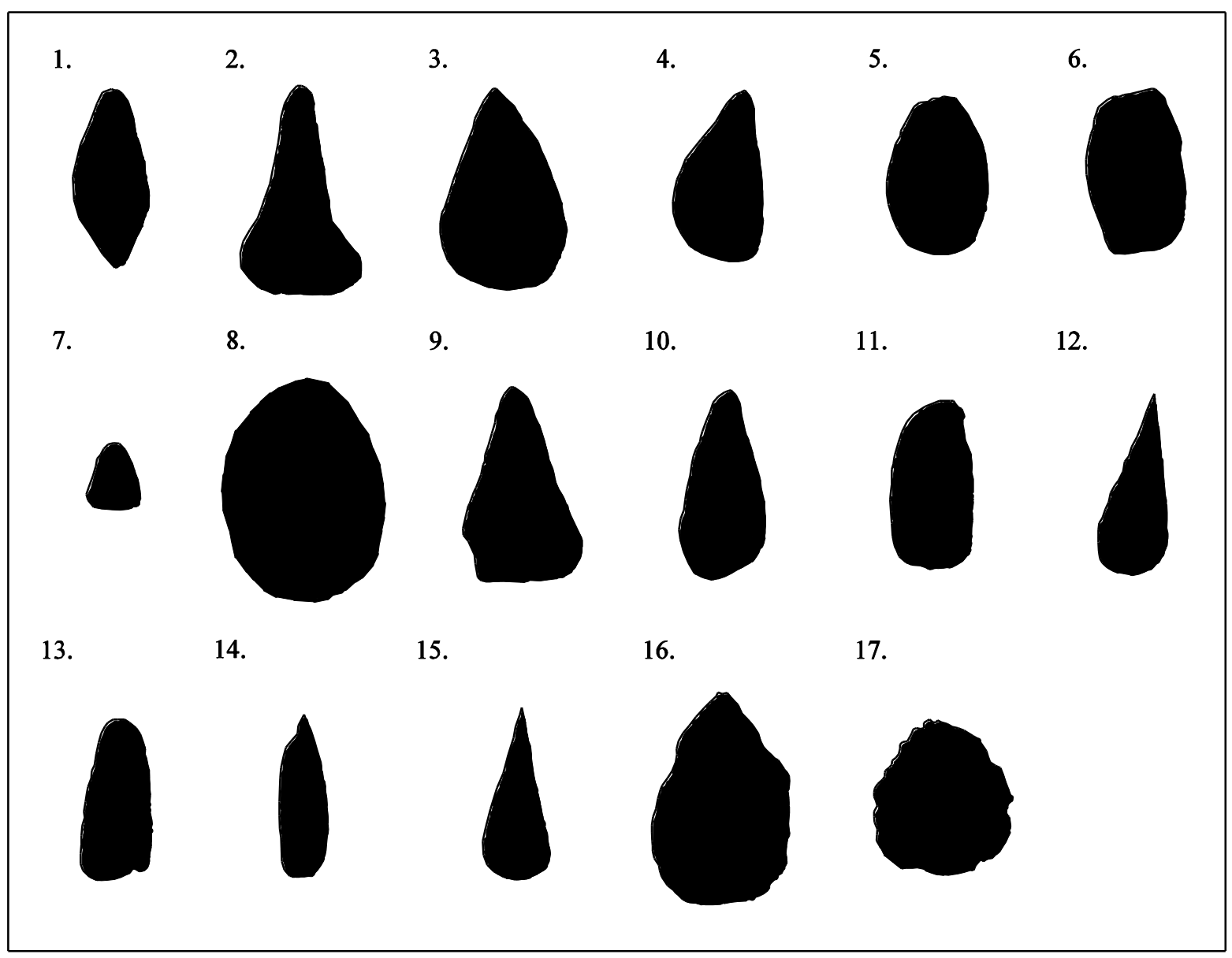

Figure 3: C.E. Bean's biface shape types (re-drawn from Bean's site notebook, held at The Dorset County Museum, Dorchester: DORCM 2005.35.AB820; (c) The Dorset Natural History and Archaeological Society at the Dorset County Museum). Individual biface outlines not to scale. 


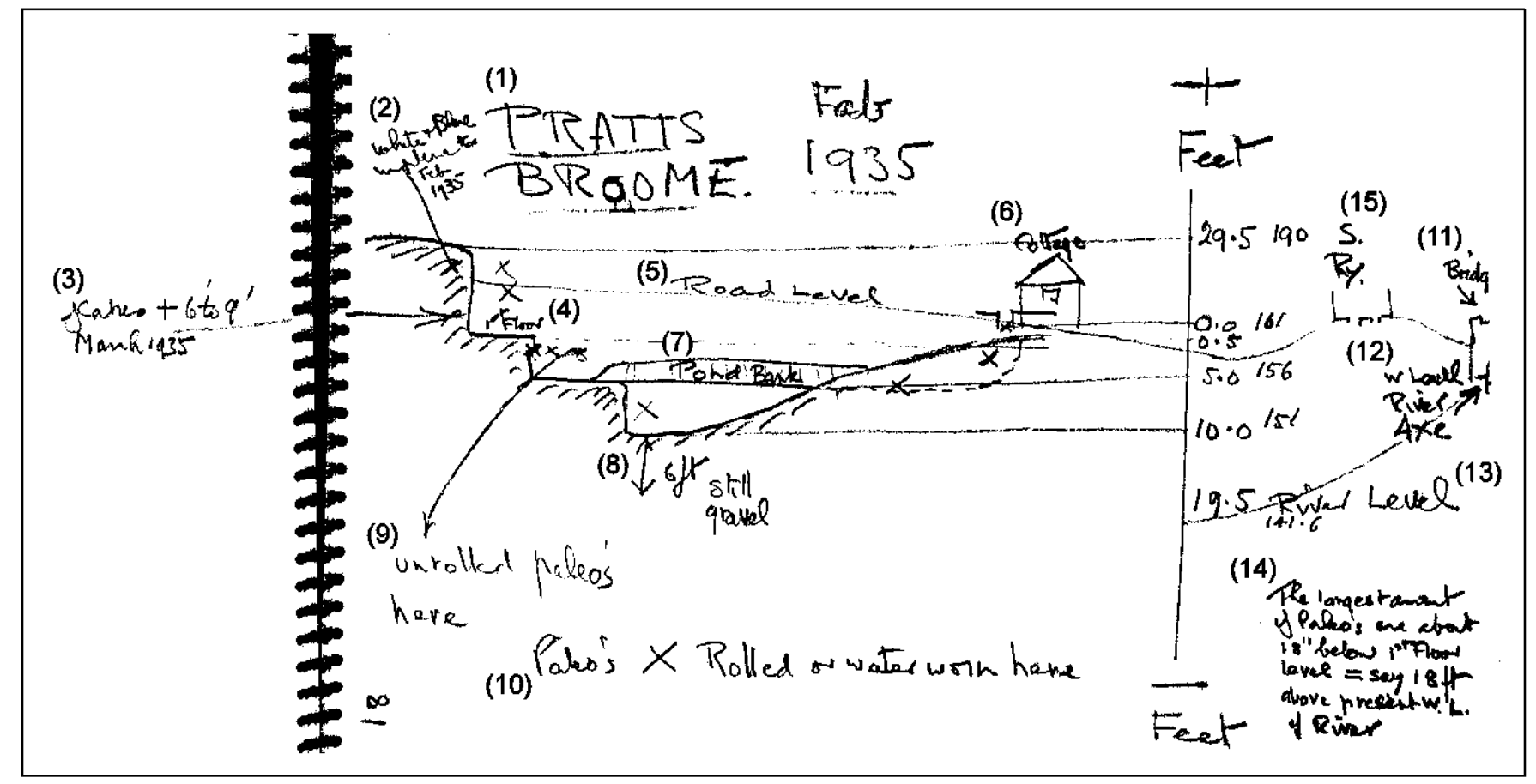

Figure 4: C.E. Bean section sketch of Pratt's Old Pit, Broom, February 1935 (modified from Bean's site notebook, held at The Dorset County Museum, Dorchester: DORCM 2005.35.AB820; @ The Dorset Natural History and Archaeological Society at the Dorset County Museum). 1: Pratts Broome Feb 1935; 2: White \& blue implements Feb 1935; 3: Flakes +6 ' to 9' March 1935; 4: $1^{\text {st }}$ floor; 5: Road level; 6: Cottage; 7: Pond bank; 8: 1 6ft still gravel; 9: Unrolled palaeo's here; 10: Paleo's X rolled or waterworn here; 11: Bridge; 12: W[ater] level River Axe; 13: River level 141.6; 14: The largest amount of paleo's are about 18 " below $1^{\text {st }}$ floor level = say $18 \mathrm{ft}$ above present W.L. [water level] of river; 15: S[outh?] R[ailwa]y. Levels OD [feet]: 190, 161, 156, 151. Levels [feet] above/below site datum (0.0): 29.5 [above], and [all below] 0.5, 5.0, 10.0, 19.5 . 


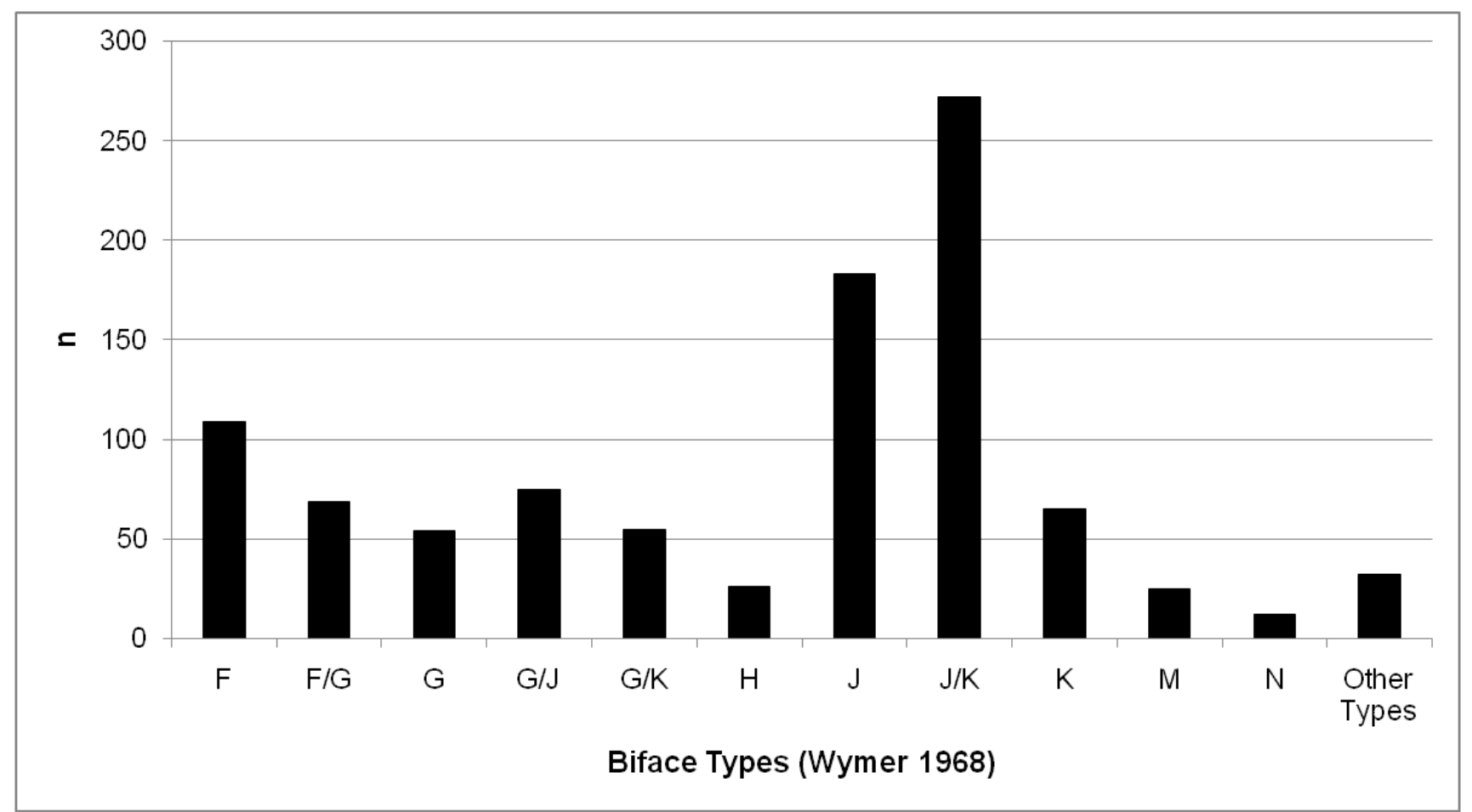

Figure 5: Biface types (after Wymer 1968) in the C.E. Bean and Exeter Museum collections. F: Pointed; F/G: Pointed/Sub-Cordate; G: Sub-Cordate; G/J: Sub-Cordate/Cordate; G/K: Sub-Cordate/Ovate; H: Cleaver; J: Cordate; J/K: Cordate/Ovate; K: Ovate; M: Ficron; N: Flat-Butted Cordate. 


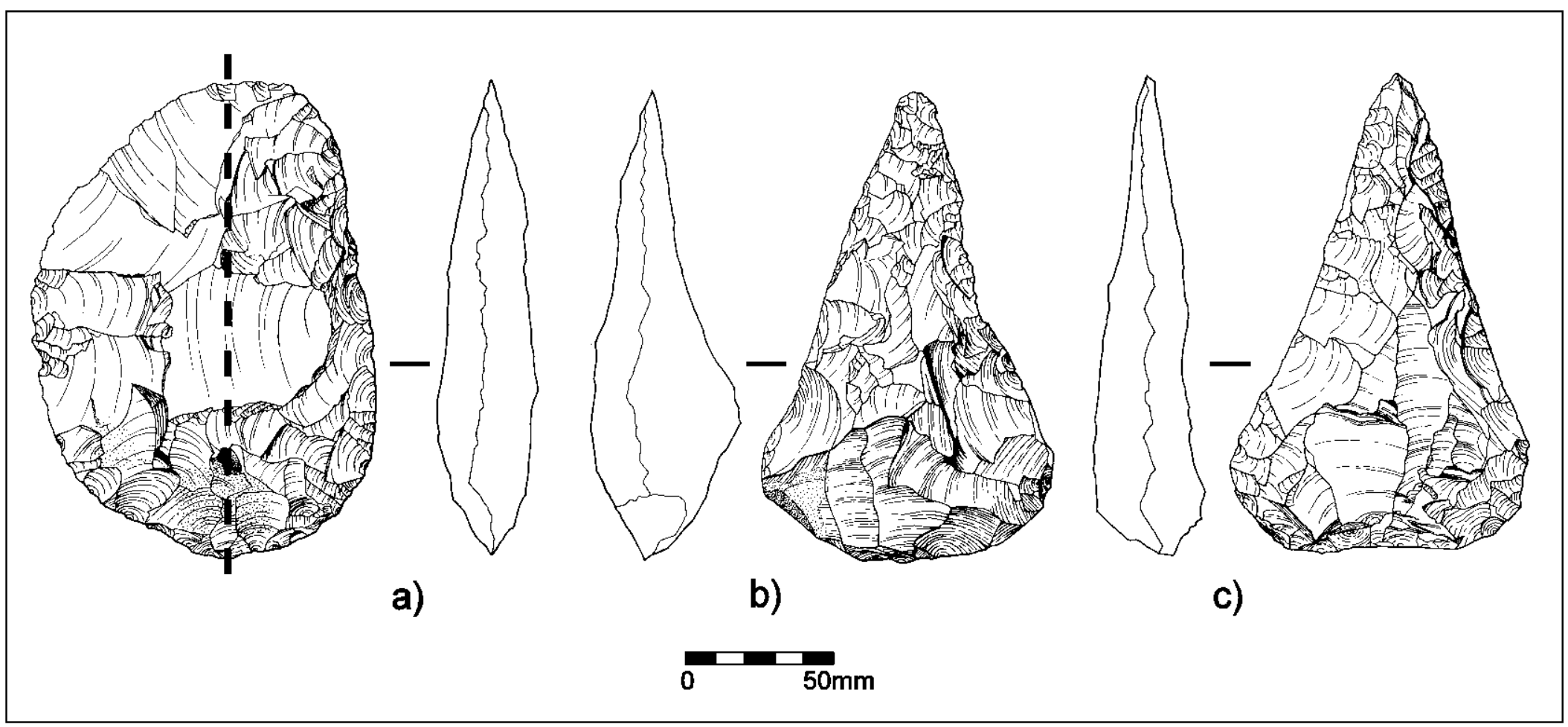

Figure 6: Examples of bifaces from Broom: a) asymmetrical forms (Bean \# 1018; FlipTest (@ Hardaker \& Dunn) index of symmetry = 8.15 [Very low symmetry]); b) \& c) points in flint (Bean \# 94; FlipTest (๑ Hardaker \& Dunn) index of symmetry = 3.15 [High symmetry]) and chert (Bean \# 85; FlipTest (๑) Hardaker \& Dunn) index of symmetry $=2.74$ [Very high symmetry]) respectively. Dashed line: axis of (a)symmetry (visual classification). Illustrations by Margaret Mathews. 


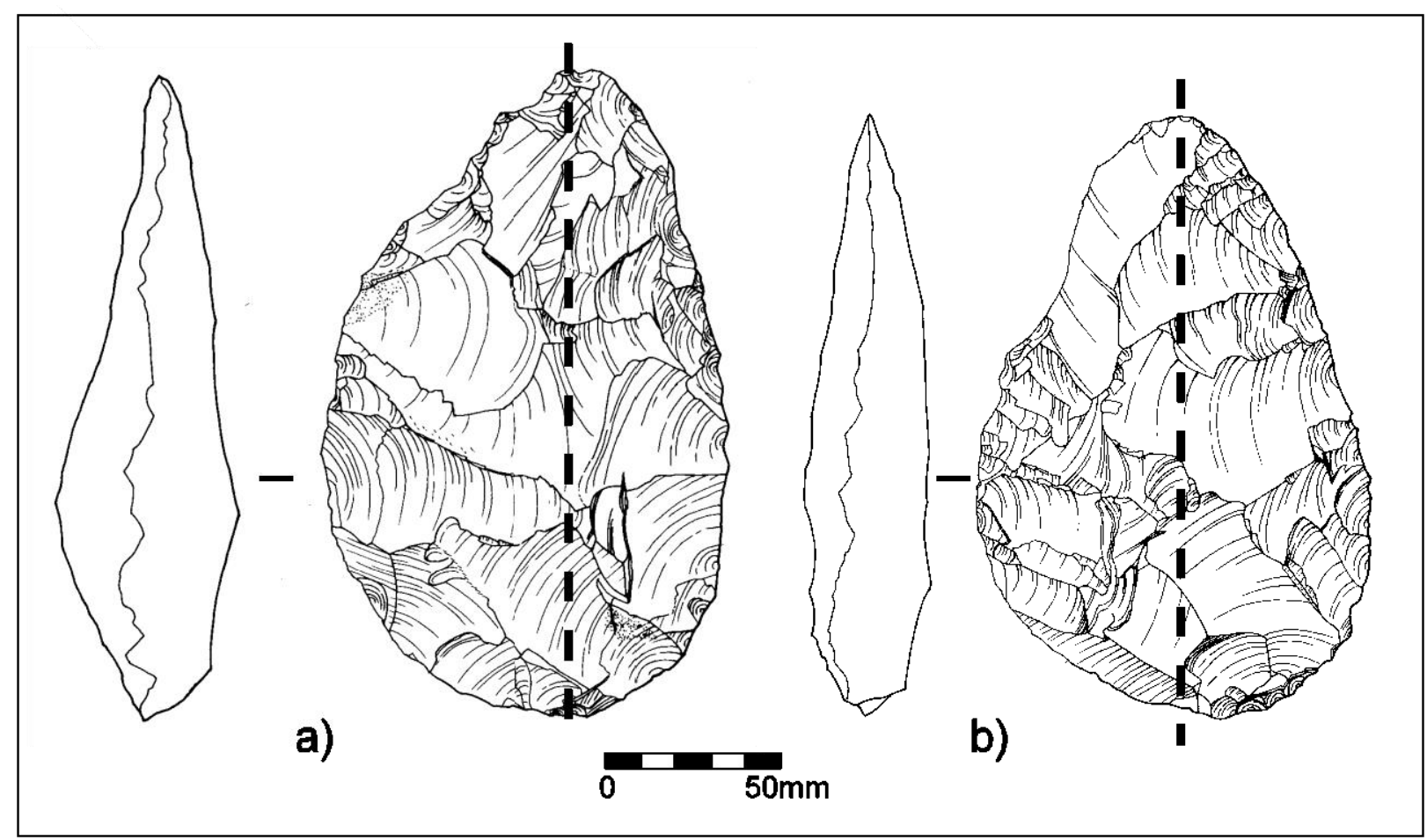

Figure 7: Examples of asymmetrical bifaces from Broom: a) Bean \# 234 (FlipTest (@ Hardaker \& Dunn) index of symmetry = 6.66 [Very low symmetry]); b) Bean \# 733 (FlipTest (@ Hardaker \& Dunn) index of symmetry = 4.53 [Moderate symmetry]). Dashed line: axis of (a)symmetry (visual classification). Illustrations by Margaret Mathews. 


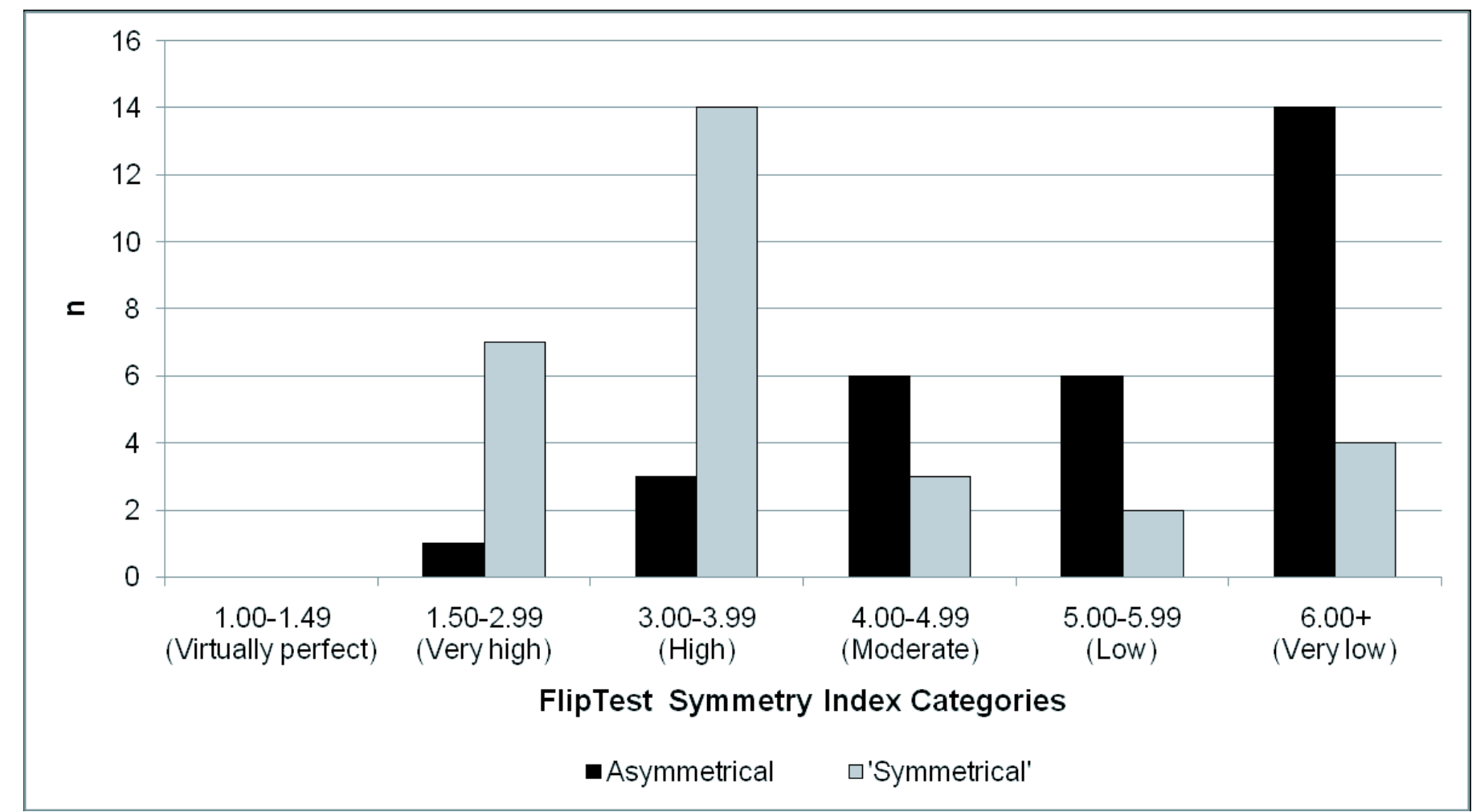

Figure 8: FlipTest (@ Hardaker \& Dunn) index of symmetry values for 'symmetrical' and asymmetrical bifaces in the C.E. Bean and Exeter Museum collections. Category descriptions after Hardaker \& Dunn (2005). 


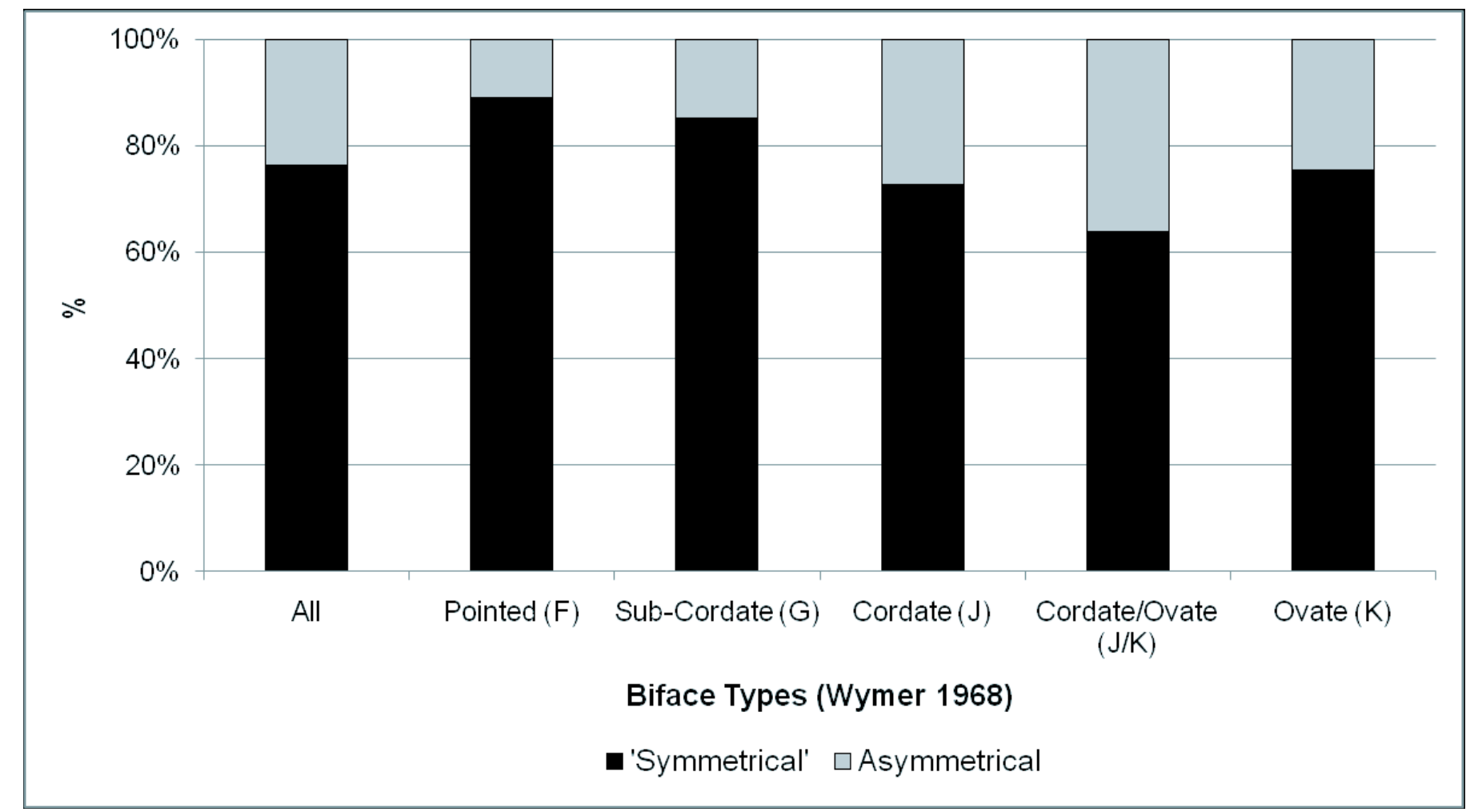

Figure 9: Proportions of asymmetrical forms across the principal biface categories (after Wymer 1968) in the C.E. Bean and Exeter Museum collections 


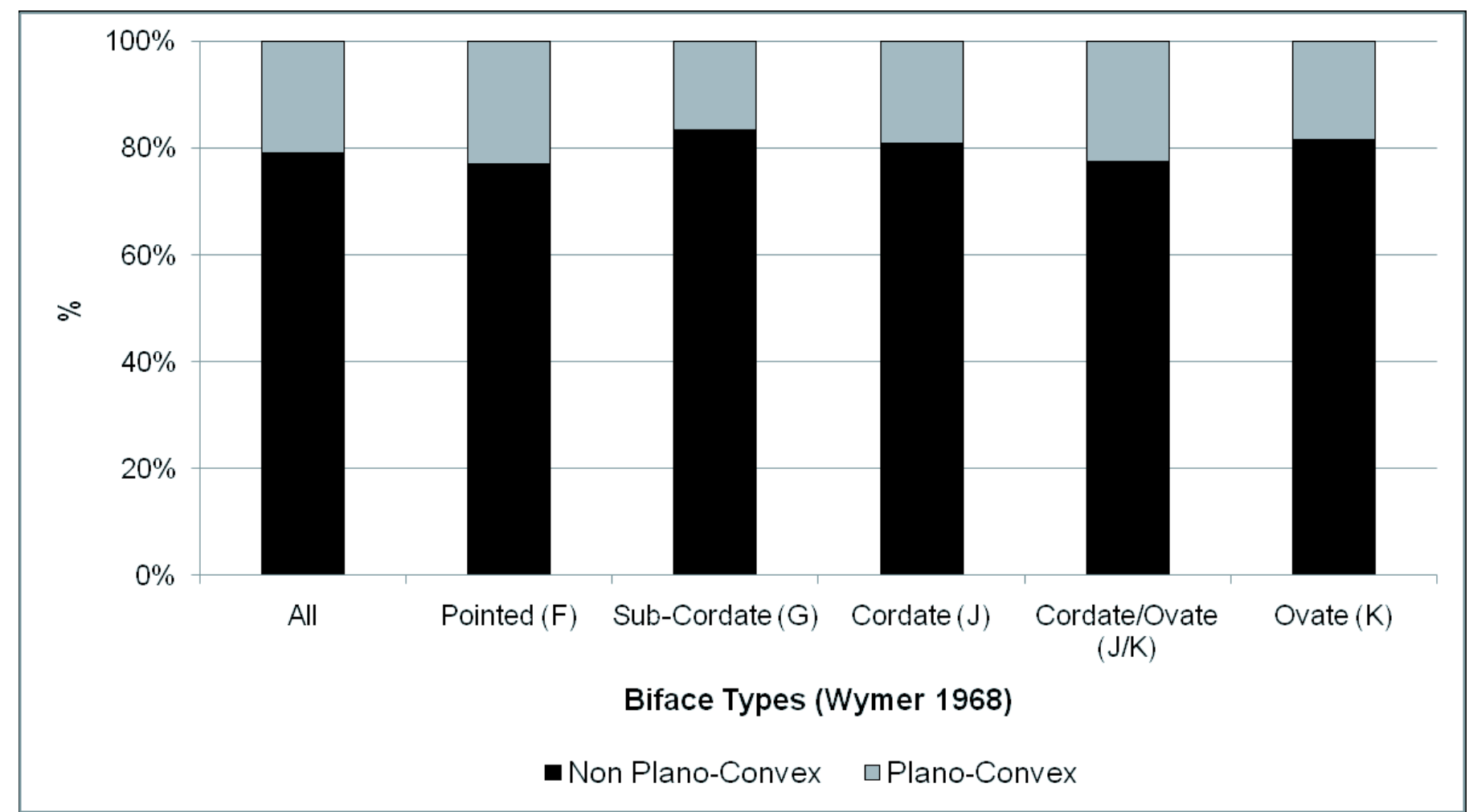

Figure 10: Proportions of plano-convex forms across the principal biface categories (after Wymer 1968) in the C.E. Bean and Exeter Museum collections 


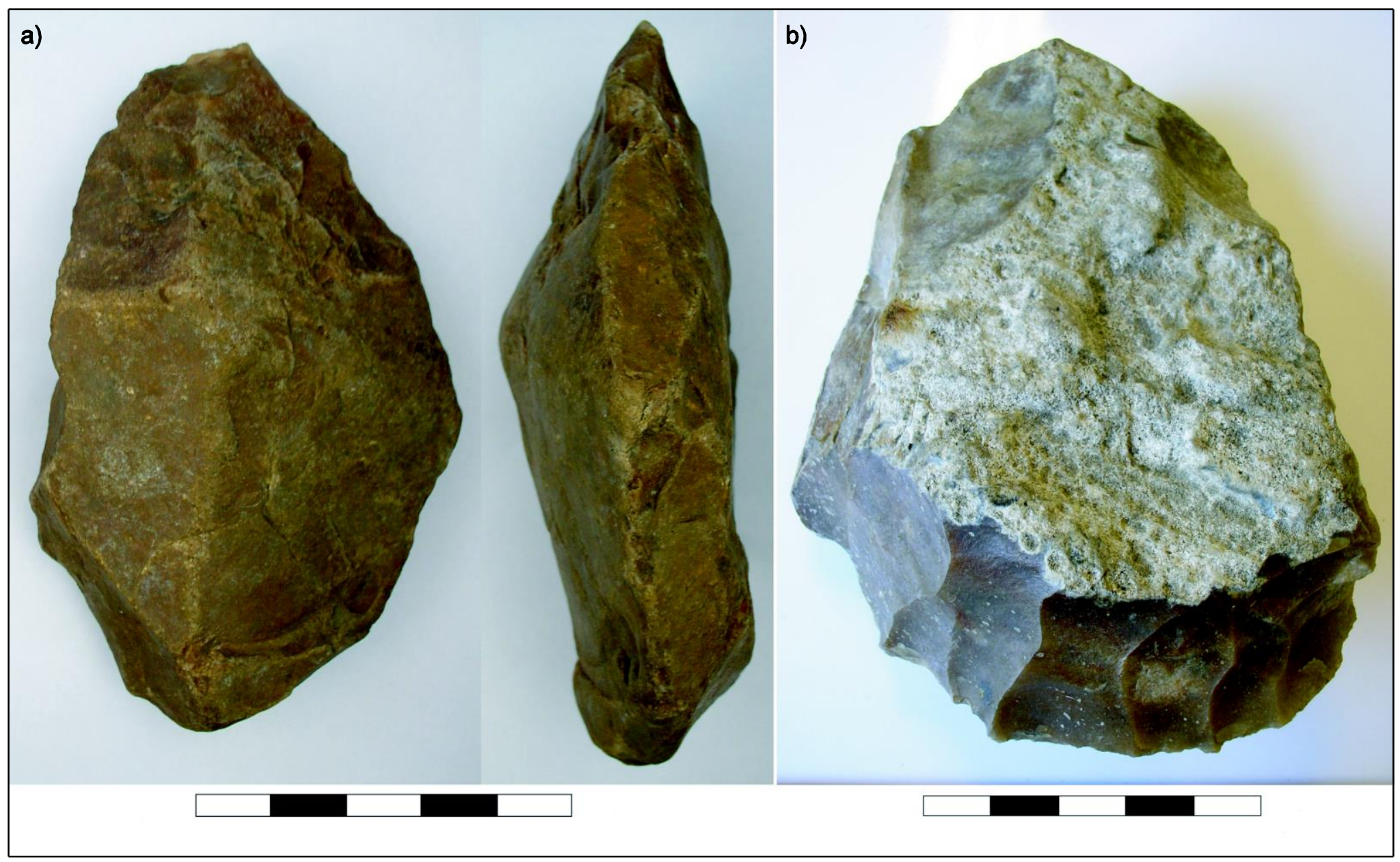

Figure 11: Chert raw materials from Broom: a) chert block collected by C.E. Bean $(25.2 \times 15.2 \times 7.2 \mathrm{~cm})$; b) parallel-flaked core collected by C.E. Bean $(35.6 \mathrm{x}$ $22.5 \times 9.8 \mathrm{~cm}) .15 \mathrm{~cm}$ scales with $3 \mathrm{~cm}$ intervals. 


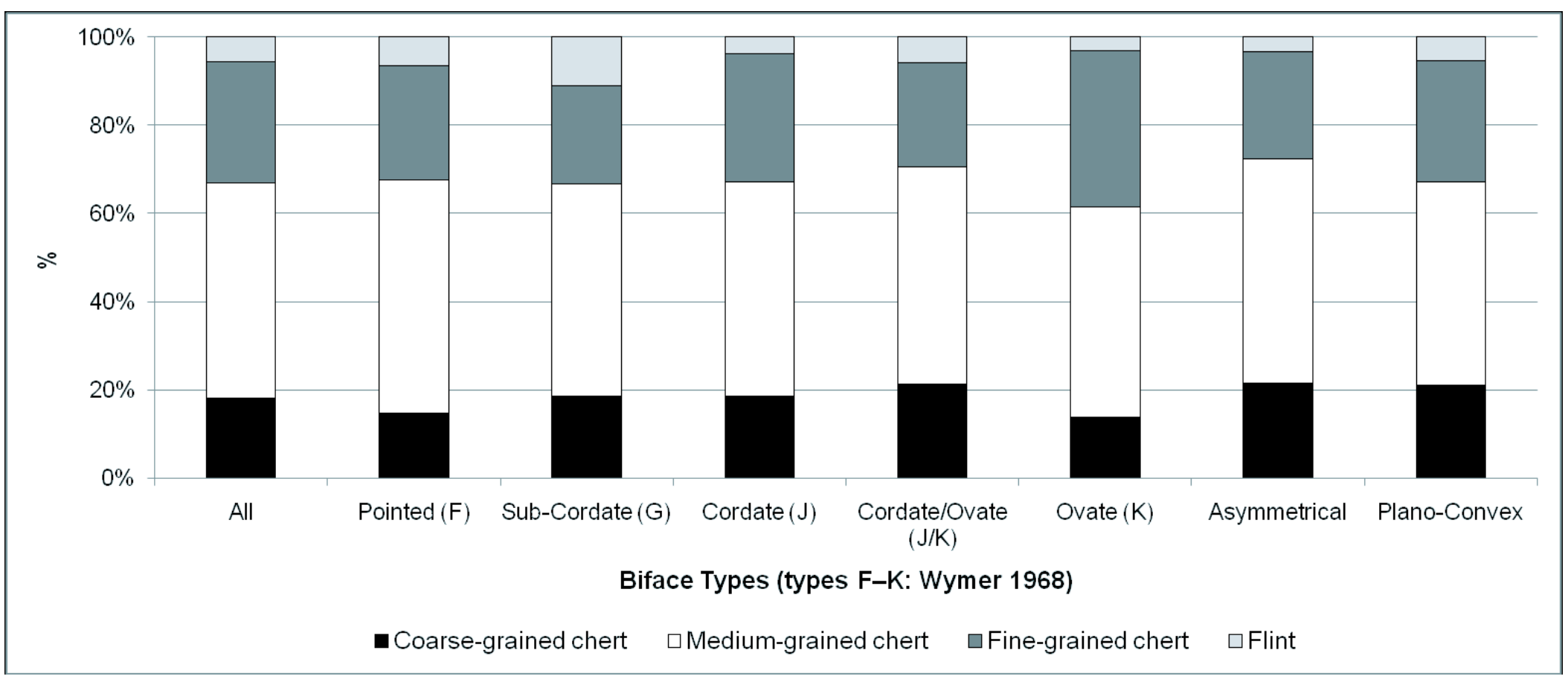

Figure 12: Proportions of raw material types across the principal biface categories (types F-K after Wymer 1968) in the C.E. Bean and Exeter Museum collections 


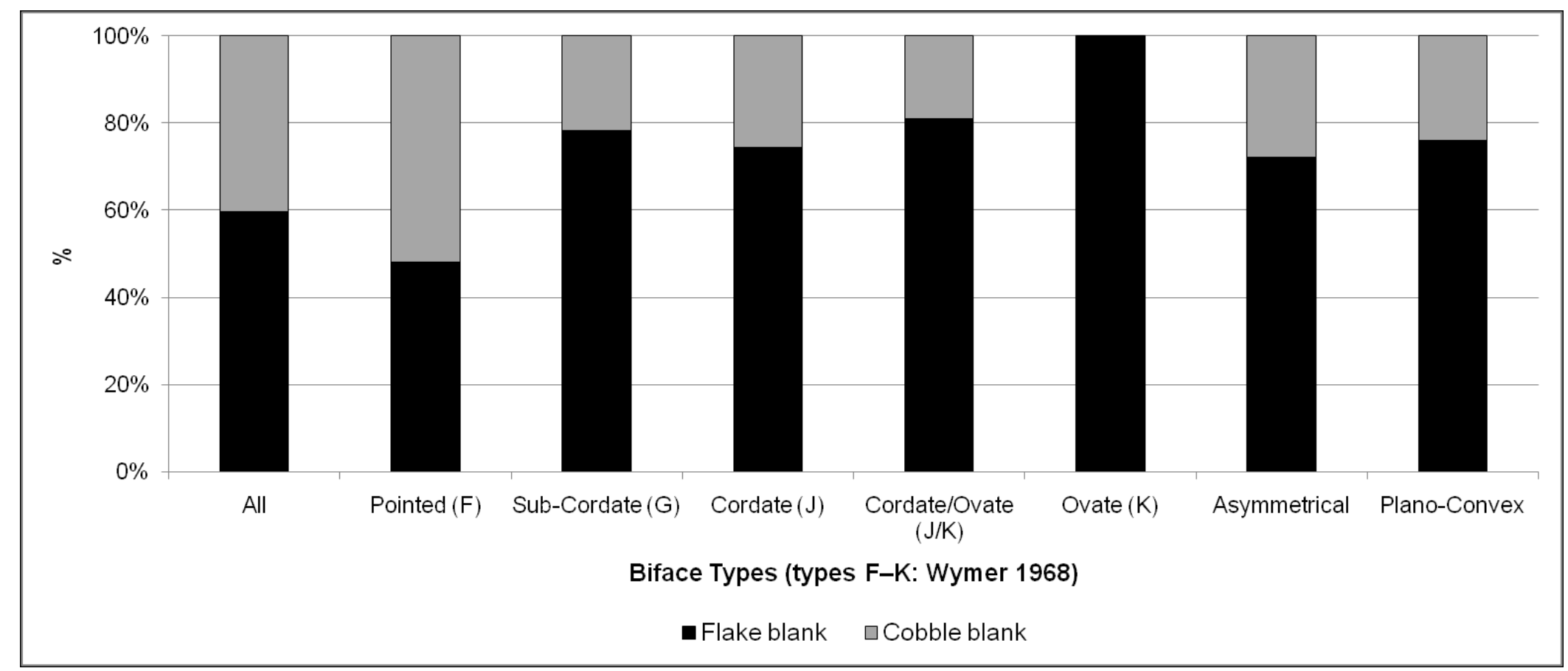

Figure 13: Proportions of blank types across the principal biface categories (types F-K after Wymer 1968) in the C.E. Bean and Exeter Museum collections 